\title{
EXUDADOS DE LA RAIZ Y SU RELEVANCIA ACTUAL EN LAS INTERACCIONES ALELOPATICAS
}

\author{
Alberto de J. Oliveros-Bastidas* \\ Departamento de Química-Grupo de Química Ecológica, Facultad de Ciencias, Universidad de Los Andes, Mérida 5101-A, \\ Venezuela \\ Francisco A. Macías, Ceferino Carrera Fernández, David Marín y José M. G. Molinillo \\ Departamento de Química Orgánica, Facultad de Ciencias, Universidad de Cádiz, Puerto Real 11510, Cádiz, España
}

Recebido em 21/2/08; aceito em 7/7/08; publicado na web em 2/12/08

\begin{abstract}
ROOT EXUDATES AND THEIR RELEVANCE TO THE ALLELOPATIC INTERACTIONS. Detrimental interactions among plants are expressed by competition for nutrients, chemical interferences and/or parasitism. Root exudates have an enormous potential at the modulation of these three mechanisms. These exudates play a key role as "phytoalexins release routes", being the allelochemicals, which regulate the chemical interactions, an example. This review presents the most recent findings on the currently used methodologies for the study of the exudation phenomenon. The methodologies for the sampling and analysis of such chemicals, as well as all other factors considered to increase the production of root exudates, are also examined.
\end{abstract}

Keywords: exudate; root; allelopathy.

\section{INTRODUCCIÓN}

El estudio de los mecanismos mediante los cuales las plantas pueden interaccionar con su entorno es muy complejo, ${ }^{1-3}$ debido principalmente a la gran diversidad de estrategias que estas utilizan para tal fin. ${ }^{4}$ Las plantas en si aprovechan todos sus órganos constitutivos para activar estos mecanismo y transmitir información a su entorno, siendo éstos específicos para cada órgano, y estos a su ves, son los que definirán el tipo de información transmitida. Así, los mecanismos que pueden ser activados en los órganos reproductivos, como la emisión de compuestos volátiles, ${ }^{5-8}$ pueden ser muy diferentes a aquellos activados o acumulados en la raíz, ${ }^{9-11}$ órgano de la planta encargado de la absorción de los requerimientos nutricionales esenciales para el crecimiento, ${ }^{12}$ y el que se encuentra en contactos directo con el suelo, soporte de la población biótica y algunos factores abióticos del ambiente donde la planta se desarrolla.

Todos estos mecanismos han sido perfeccionados evolutivamente, ${ }^{13-15}$ y como característica heredada de la planta, su desarrollo y manifestación no sigue un plan prediseñado, y por el contrario, el mismo se encuentra siempre sujeto a constantes modificaciones que se expresan en una plasticidad adaptativa como consecuencia de su interacción con su medio ambiente. ${ }^{16}$ Es esta propiedad la que le ha conferida a las plantas una alta capacidad de adaptarse y soportar las más diversas condiciones, no solo de tipo física, sino a las generadas por agentes bióticos. En términos generales, los mecanismos de interacción de las plantas con su entorno, aplicados para lograr su supervivencia como objetivo fundamental, pueden ser divididos en dos grandes grupos según su naturaleza. Un primer grupo está representado por aquellos mecanismos de tipo físico y de arquitectura de la planta, donde pueden incluirse características de velocidad de crecimiento, rasgos anatómicos de la hoja y el tallo, dormancia a largo tiempo y condiciones de sus cariópsides, mecanismo de reproducción, modos duales de reproducción, plasticidad ambiental, resistencia a condiciones adeversas, la germinación no requiere condiciones especiales, rápida reposición de organos perdidos, capacidad de desarrollar resistencia frente a medidas de control, alta capacidad de competencia, entre otras propiedades.

\footnotetext{
*e-mail: aloliver@ula.ve
}

En estos mecanismos, considerados mucho más activos desde el punto de vista fisiológico, ${ }^{17}$ la planta invierte una cantidad importante de su capacidad metabólica en sintetizar transmisores de información, muchas veces metabolizados en altas concentraciones en períodos cortos de tiempo, sacrificando energía y fijación de carbono, en detrimento de otras funciones vitales de la planta, como su crecimiento.

Estos mecanismo son pasivos desde el punto de vista de respuesta al estrés, pues los mismos han sido adquirido y perpetuados evolutivamente, y representan rasgos que le son característicos a las plantas, y difícilmente serán modificados una vez que las plantas se adapten a unas determinadas condiciones. El segundo grupo lo constituyen aquellos mecanismos de tipo químico, donde la manifestación en cada uno de los procesos involucrados lo representa los compuestos químicos, generalmente metabolitos secundarios, encargados de transportar la información que en ese momento es vital para la supervivencia de la planta, como lo representan aquellos liberados mediante exudado de raíz.

Al contrario de los mecanismos de tipo físicos, los químicos si son susceptibles de ser modificados con cambios del entorno de la planta, ${ }^{18}$ en periodos de tiempo dentro de su ciclo de vida, los cuales representan un sistema adaptativo muy eficaz, con una rápida respuesta a las modificaciones o fluctuaciones de su entorno. Sin embargo, para que los mecanismos mediados por agentes químicos sean efectivos, no solo es necesaria su biosíntesis y acumulación por parte de la planta, si no que dicho mecanismo tiene que contener un operador que indique las rutas mediante las cuales este metabolito sintetizado pueda ser liberado al ambiente, donde la información que lleve consigo pueda ser insertada en las interrelaciones del nicho ecológico donde la planta se encuentra. ${ }^{19}$

De esta manera, el mecanismo no solo contiene la información necesaria para su metabolización, sino que al mismo tiempo active procesos fisiológicos para su excreción de una manera activa y efectiva, ${ }^{3}$ de tal manera que sea capaz de transmitir la información en el lugar, momento y tiempo adecuados. El estudio de todos los diferentes mecanismos de intersección en un ecosistema dado es fundamental para entender los fenómenos de asociación existentes entre plantas, que de alguna manera regulan sus patrones poblacionales observados. Muchos de estos mecanismos frecuentemente 
operan simultáneamente. Así, las estrategias de crecimiento están sincronizadas con la excreción de sustancias hacia el medio. Su acción conjunta, contribuye a definir los patrones poblacionales observados macroscópicamente, como el dominio de una especie en un espacio bajo determinadas condiciones. Cuando diferentes mecanismos están actuando simultáneamente, suele definirse al fenómeno total como interferencia entre especies, ${ }^{20,21}$ sin embargo, cuando los fenómenos está relacionado sólo con la intermediación negativa de compuestos químicos liberados el fenómeno se ha denominado Alelopáticos, y a los metabolitos secundarios que son responsables de los efectos son denominados aleloquímicos. De esta manera, la interferencia comprende los mecanismos de competencia física y de alelopatía simultáneamente.

\section{ALELOPATIA}

Desde el punto de vista etimológico el término Alelopatía, significa perjuicio mutuo, término compuesto por dos palabras, "allelon" ("de uno a otro") y "pathos" ("sufrir"). ${ }^{22}$ La definición más tradicional del fenómeno de alelopatía, es la postulada por Rice ${ }^{23}$ descrito como "cualquier efecto directo o indirecto causado por una planta (incluyendo microorganismos) sobre otras a través de la producción de compuestos químicos que escapan al medio ambiente". Con el espíritu de englobar muchas otras interacciones, una definición más amplia, es la desarrollada por la Sociedad Internacional de Alelopatía en $1996,{ }^{24}$ definiéndola como: "cualquier proceso que involucre metabolitos secundarios producidos por plantas, algas, bacterias y hongos, que influyan en el crecimiento y desarrollo de sistemas biológicos y agrícolas".

De este modo, el término de alelopatía se refiere al conjunto de interacciones entre especies de plantas, que en un balance general, se traduce en un efecto perjudicial a una de ellas para aumentar la prevalencia de la especie productora. ${ }^{3,25}$ Aunque el término alelopatía es comúnmente usado para describir las interacciones químicas entre dos plantas, éste también ha sido usado para describir la comunicación microbio-microbio y planta-microbio. ${ }^{26-28}$ Sin embargo, dependiendo de cada sistema y de las condiciones de trabajo, han sido introducidas otras definiciones para describir el fenómeno, como por ejemplo, en los estudios realizados por Inderjit y Dakshini ${ }^{27}$ en sistemas acuáticos, definiendo la alelopatía como "un fenómeno donde las alomonas generadas por las algas pueden afectar: otra alga en su vecindad, su propio crecimiento, la asociación con los microbios, plantas superiores de su vecindad y acumulación y disponibilidad de iones nutrientes; los cuales influyen sobre la distribución, crecimiento y establecimiento de otras algas, microorganismos y plantas". A diferencia de las dos anteriores, esta representa una definición más precisa y detallada del sistema al que hacen referencias (sistemas acuáticos). Así como esta definición, han sido descritas otras, tales como "mecanismo de interferencia mediante el cual una planta libera una sustancia que afecta a otra planta", 29 "el efecto negativo de una sustancia liberado por una especie de planta sobre el crecimiento y reproducción de otra"; 30 "la liberación extracelular de compuestos que inhiben el crecimiento de otros microorganismos"; 31 "supresión del crecimiento de la planta vecina por la liberación de compuestos tóxicos"; 32 "la liberación de compuestos químicos por un invasor que tiene efectos perjudiciales sobre los miembros de la comunidad de plantas hospederas"; ${ }^{25} \mathrm{y}$ "la supresión química de especies de plantas competidoras". ${ }^{33}$

A pesar de que la alelopatía restringe en si el fenómeno de interacción entre las plantas sólo donde intervienen compuestos químico, el problema de su estudio sigue siendo dinámico y muy complejo. Por ejemplo, la manera de cómo el aleloquímico puede intervenir en los efectos observados sobre otras plantas pueden ser variados, influyendo de una manera directa sobre el crecimiento de otra planta, de una manera indirecta, originando productos biotransformados que son los verdaderos agentes activos, interaccionando con sustratos biótico y abióticos, o en el caso más complejo, induciendo la liberación de aleloquímico por una tercera planta de su entorno (Tabla 1). ${ }^{34-36}$

Tabla 1. Posibles formas de actuación de los aleloquímicos en un ecosistema

\begin{tabular}{lcc}
\hline Tipo & Características & Ref.* \\
\hline I & $\begin{array}{c}\text { ACCIÓN DIRECTA DEL ALELOQUímiCO ENTRE PLANTAS } \\
\text { (CONCEPTO FUNDAMENTAL DE ALELOPATÍA) }\end{array}$ & 37,38
\end{tabular}

La planta A produce un compuesto $\mathbf{X}$, el cual interfiere negativamente con una planta $\mathbf{B}$

II INTERACCIÓN DIRECTA CON LA ECOLOGÍA DEL SUELO

A.- Alelopatía indirecta

1. Alelopatía entre planta-planta mediada por fenómenos de descomposición

Una planta A produce un compuesto $\mathbf{X}$, el cual es degradado y/o transformado por un microorganismo $\mathbf{C}$ a un compuesto $\mathbf{Y}$, el cual interfiere con la Planta B.

2. Alelopatía inducida.

La planta A produce un compuesto $\mathbf{X}$ en cual es liberado e induce a un organismo $\mathbf{D}$ a producir un compuesto $\mathbf{Z}$ el cual interfiere con la Planta $\mathbf{B}$.

\section{B.- TOXICIDAD INDIRECTA}

Un compuesto $\mathbf{X}$ interacciona con el ecosistema de suelo y causa la generación de un compuesto $\mathbf{Z}$ (éste no es producto de descomposición de $\mathbf{X}$ ), el cual interfiere con la Planta $\mathbf{B}$.

\section{C.- Efectos AmbiÉntales directos}

Un compuesto $\mathbf{X}$ causa cambios en el ambiente del suelo, el cusa afecta el estatus de nutrientes en el suelo, reduciendo de esta manera el crecimiento, supervivencia o reproducción de la Planta $\mathbf{B}$, sin efectos tóxicos.

* Referida a las observaciones experimentales donde se apoya la hipótesis

\section{LA RUTA NATURAL DEL FENOMENO ALELOPÁTICA}

Siendo los aleloquímicos los entes transmisores de información, es lógico pensar que éstos son los responsables de la existencia y potenciabilidad del fenómeno, estando los estudios dirigidos sobre éstos desde diferentes puntos de vista, ${ }^{35,44,45}$ lo que ha propuestos directrices al momento de estudiar la existencia del fenómeno. En este sentido, siete niveles de estudio han sido propuestos al momento de abordar el mecanismo o ciclo alelopático: ${ }^{34,35}$ determinar la presencia y subsiguiente liberación del aleloquímico por una planta denominada donadora: ${ }^{46-54}$ detectar la inhibición del crecimiento sobre una segunda planta, denominada receptora; ${ }^{55,57}$ estudiar el destino final del aleloquímico en el suelo, que modulara la naturaleza de su actuación y las especies verdaderamente activas ${ }^{58-63}$ determinar el movimiento del aleloquímico en el suelo, que determinara los niveles de concentración y tiempo de difusión, además de demostrar su absorción por la especie de planta receptora; ${ }^{64-73}$ detectar la posible respuesta de defensa por parte de la planta receptora, activando mecanismo que le permitan atenuar o minimizar el efecto del aleloquímico, como por ejemplo, procesos como la detoxificación; ;,74-81 estudiar el efecto 
del aleloquímico, una vez liberado, sobre la ecología del suelo y la circulación de nutrientes en el mismo; ${ }^{82-91}$ estudiar la presencia del efecto de agentes promotores, inhibidores, y sustancias neutras en el suelo. ${ }^{92-94}$ Sin embargo, cualquiera que sean las propiedades de los compuestos detectados en la planta, características tales como actividades biológicas diversas, tiempo de vida media en el suelo, especificidad a un restringido grupo de organismos, ser inocuo para la especie donadora; entre otras propiedades, son las exigidas para ser considerado como un aleloquímico..$^{95}$

No obstante, ninguna de estas característica tendrán algún significado ecológico, si este aleloquímico no es transmitido al ambiente por un mecanismo lo suficientemente efectivo para garantizar un nivel de concentración toxico. Es por este hecho que la detección y búsqueda de los mecanismos de liberación de los aleloquímicos se consideran pasos primarios en el estudio de las interacciones planta-planta. Estos aleloquímicos pueden ser divididos en alomonas, ${ }^{96,97}$ kairomonas, ${ }^{98}$ sinomonas ${ }^{97}$ y apneumonas, ${ }^{96,97}$ segúna el efecto provocado o el origen del mismo. En general, siendo metabolito secundarios, tienen como rasgo característico común, el ser compuestos con un peso molecular relativamente bajo que ayudara a su circulación dentro de la planta (movimiento, traslocación, compartimentación, etc.), ${ }^{99,100}$ y así su posible excreción, sin embargo, es la función fisiológica de la planta quien determina si este es excretado al ambiente, iniciando de esta manera las interacciones con los diferentes entes que lo conforman. Ecológicamente, se han propuestos cuatro mecanismos para la excreción de los aleloquímicos al ambiente, donde cada uno de ellos han demostrado la eficacia de tal mecanismo, involucrando fenómenos de volatilización, ${ }^{101-107}$ lixiviado, ${ }^{108-113}$ descomposición de partes de la planta en el suelo ${ }^{114-118}$ y exudados por raíz. ${ }^{119-127}$ Estos mecanismos implican que los aleloquímicos pueden encontrase en cualquier parte de la planta, y que la dinámica de su actividad es una función del mecanismo en que este pueda ser liberado. Por ejemplo, la descomposición de residuos vegetal implica material senescente, que no implica una función activa de la planta, mientras que volatilización y exudados de raíz, son procesos extremadamente activos donde está involucrado el tejido vivo de la planta. ${ }^{128,129} \mathrm{El}$ conocimiento de las bases químicas que gobiernan el fenómeno de la alelopatía necesariamente implican el estudio de los mecanismo de liberación o excreción y los efectos que los agentes liberados puedan producir sobre un organismo receptor, y en particular, sobre un planta receptora, pues en este caso, solo son válidas las rutas de interacción que impliquen la existencia de tejido vivo, tanto de la especie donadora del xenobiótico como la receptora.

En este sentido, no es sorprendente que los compuestos químicos presentes en los exudados de raíz hayan sido catalogados como las claves fundamentales en estos estudios, ${ }^{130,131}$ donde participa el suelo como estructura base del crecimiento de las plantas, y en consecuencia, la vía por donde deben de transitar los aleloquímicos liberados, y superar en este tránsito, muchos obstáculos, por lo que ha sido una variable más en el estudio del fenómeno alelopático. Es por ello, que el estudio de los exudados de raíz sea de carácter obligatorio al momento de establecer la acción alelopática en un sistema. Con esto, se discutirán en lo sucesivo, el fenómeno de exudado de raíz, considerando las características básicas del proceso de exudación, hasta los factores que pueden modular el tipo y cantidad de químicos presentes en estos compuestos.

\section{LA RAÍZ Y SUS EXUDADOS}

La arquitectura radicular de una planta, referida comúnmente como "la mitad oculta, ${ }^{132,133}$ está compuesta por un órgano subterráneo de forma lineal con patrones de arquitectura y crecimiento muy complejos, ${ }^{134-137}$ estando el sistema radicular en sí definido principalmente por el tipo de planta, la estructura del suelo, y las interacciones entre los dos. ${ }^{138}$ Mientras que la forma de las hojas y otros órganos pueden ser interpretados como adaptaciones a un ambiente o condiciones ambientales, esta situación no es paralela a lo ocurrido en las partes subterráneas de las plantas. En el ambiente de la raíz son muy pocas las variaciones significativas encontradas, y por ello, la carencia de variaciones importantes en los rasgos externos o morfológicos de las raíces. Sin embargo, se ha registrado una cierta plasticidad fenotípica, pues el ambiente, aunque macroscópicamente homogéneo, es micro heterogéneo, pero lo suficiente para ser detectado por la raíz durante su crecimiento, tanto en el tiempo como en el espacio, ${ }^{139} \mathrm{y}$ es gracias a esta plasticidad la que le ha permitido al sistema radicular desarrollar raíces fibrosas llamados "cabellos radiculares", cuya función primordial ha sido asociado al anclaje de la planta con el medio suelo. ${ }^{139,140}$ Además de esta función, las raíces también poseen otras, no tan obvias, que le confieren una importancia vital para la supervivencia y ecología de la planta, por ser además un sitio con una alta actividad fisiológica, dando origen a la síntesis, acumulación y liberación de compuestos, que interfieren en los patrones poblacionales intra e inter especie.

\section{LA RIZOSFERA Y SU COMPOSICIÓN}

El sistema radicular en conjunto posee, de manera diferencial, una resaltante habilidad para secretar compuestos con una gran diversidad de propiedades físicas y químicas a la rizósfera, como una respuesta al estrés o fluctuaciones de tipo tanto bióticas como abióticas donde estas se encuentran, definiéndose como rizósfera a los gradientes longitudinales y radiales donde ocurre la expansión de las raíces durante su crecimiento, adquisición de agua, nutrientes, exudación, y subsiguiente crecimiento microbial, ${ }^{138}$ localizada desde la superficie de la raíz hasta $2 \mathrm{~mm}$ de distancia de esta, siendo la zona del suelo que más sufre los efectos producidos por los compuestos liberados por la raíz. Sin embargo, esta distancia no es absoluta, siendo dependiente de las propiedades del suelo, como lo es el tamaño de partícula, contenido de agua y la capacidad reguladora del $\mathrm{pH} .{ }^{141,142}$ Otras definiciones más especializadas surgen de las actividades que ha sido posibles registrar en esta zona, donde el concepto de volumen de suelo que está influenciado por la actividad propia del sistema de raíz de la planta, suele ser la definición más específica y concertada. ${ }^{143}$ A partir de este concepto de rizósfera, se define el fenómeno de rizodeposición, referida como la liberación de toda forma de carbono a partir de las raíces. Los productos de la rizodeposición pueden ser categorizados como exudados, secreciones y grasas. La diferencia existente entre exudados y secreción, es que para el exudado, los compuestos son pasivamente liberados, mientras que en la secreción lo son activamente. En las secreciones se incluyen a los carbohidratos poliméricos y enzimas. ${ }^{144}$ Los exudados incluyen compuestos de peso molecular altos, como mucílago, un material gelatinoso en la superficie de las raíces; ${ }^{145,146}$ y dentro de los compuestos de bajo peso molecular, se encuentran ácidos orgánicos, azúcar, fenólicos simples, aminoácidos, flavonoides ${ }^{147} \mathrm{e}$ incluso vitaminas, ${ }^{148,149}$ y son éstos los de mayor interés al momento de evaluar las transmisión de información al medio por parte de las plantas.

En la literatura se encuentran diferencias significativas del término exudación, estrictamente Exudado fue primero descrito como compuestos de bajo peso molecular que difunden pasivamente a partir de las células intactas a la solución de suelo. ${ }^{150}$ Sin embargo, "exudado de raíz" es frecuentemente usado para describir más generalmente a los compuestos de bajo peso molecular liberados, más que el proceso mediante el cual estos son depositados dentro de la rizósfera. De esta manera, es en la rizósfera donde se encontraran toda la carga fitoquímica liberada por la planta, y la zona donde es de 
esperar se encuentre la máxima actividad ejercida por los compuestos, o ejercida sobre ellos, como es el caso de la biodegradación, y así es la zona que está siendo estudiada en la búsqueda de los agentes verdaderamente activos.

\section{COMPOSICIÓN QUÍMICA DE LOS EXUDADOS DE LA RAÍZ}

Las raíces primarias, secundarias y sus cabellos radiculares, genéricamente son capaces de liberar cantidades significativas de exudados. El proceso en si depende en forma general de la especie de planta, ${ }^{17,151-153}$ presencia de microbios, ${ }^{154,155}$ estatus nutricional ${ }^{156,157}$ y agua de la planta, ${ }^{158,159}$ disponibilidad de oxígeno, ${ }^{160,161}$ medio de desarrollo ${ }^{162,163} \mathrm{y}$ otras condiciones de crecimiento. ${ }^{164-167}$ Como se señalo, las raíces exudan una variedad importante de compuestos de, donde se incluyen azúcares y polisacáridos simples (tales como arabinosa, fructuosa, glucosa, maltosa, manosa y oligosacaridos), aminoácidos (tales como arginina, asparganina, cisterna y glutamina), ácidos orgánicos (tales como ácido acético, ascórbico, benzoico, ferúlico y málico) y compuestos fenólicos (Tabla 2), muchos de los cuales poseen actividades y funciones demostradas. ${ }^{168-170}$ Dentro de los compuestos exudados con mayores pesos moleculares encontramos los flavonoides, enzimas, ácidos grasos, reguladores del crecimiento, esteroides, carbohidratos, alcaloides, poliacetilenos, etc. Así, existe una gran diversidad estructural en los exudados de la raíz, que van desde moléculas relativamente sencillas hasta moléculas más complejas estructuralmente, como flavonoides y alcaloides. Además de esto, los niveles registrados pueden variar, entre otros factores, como una respuesta a estímulos externos a la planta, tales como variaciones en las condiciones propias del ambiente, como la temperatura y la intensidad y composición de la radiación, lo que le han conferido a la raíz de un sistema de defensa muy dinámico, además de la tradicional y obvia función de soporte y toma de agua y nutrientes. Por otra parte, los exudados de raíz representan una de las fuentes más directa de compuestos químicos a la rizósfera, y como consecuencia, el fenómeno que más importancia tiene en el estudio de la biología y bioquímica de los procesos que tienen lugar en esta "parte oculta" de la planta. ${ }^{81-91}$ Desde este punto de vista, los exudados representan la clave fundamental en los efectos alelopáticos observados en las plantas superiores, y las variaciones que se encuentran tanto en su composición como en sus concentraciones, reflejaran el dominio del fenómeno alelopático en los patrones poblacionales observados. De aquí nace la importancia de estudiar el comportamiento de los niveles de estos aleloquímico en exudados de raíz, bajo diferentes variables, como elemento fundamental en el mecanismo de acción alelopática y las consecuencias que desde esto se desprenden.

\section{COMPUESTOS QUÍMICOS EN LOS EXUDADOS DE LA RAÍZ CON POTENCIAL ALELOPÁTICO}

Dentro de la gran variabilidad de compuestos químicos aislados de los exudados de la raíz, muchos han mostrado actividades biológicas relevantes, incluso semejante a los mostrados por algunos agentes sintéticos tales como los herbicidas, ${ }^{171}$ donde podemos citar $\alpha$-tertienil, ${ }^{172}$ artemisina, ${ }^{173}$ sorgoleone, ${ }^{174,175}$ momilactona A, ${ }^{176}$ momilactona $\mathrm{B},{ }^{177}$ 2,4-dihidroxi-2H-1,4-benzoxazin-3(4-H)-ona (DIBOA), ${ }^{178}$ 2,4-dihidroxi-2H-1,4-benzoxazin-3(4H)-ona (DIMBOA), ${ }^{179}$ pisatin, ${ }^{180} \omega$-metilsulfonilalquil isotiocianatos (tiosanatos), ${ }^{181}$ desoxihemigosipol (terpenoides), ${ }^{182}$ cineole, ${ }^{183}(+)$ - $\alpha$-bisabolol,,${ }^{184}$ parteina, (+)-estrigol, ${ }^{185,186}$ ginsenosides (saponinas), ${ }^{187} 7$-Hidroxi-6metoxicoumarina (escopeletin), ${ }^{188} 7$-hidroxicumarina (umbelliferona), ${ }^{189}$ y fenólicos simples en general (Figura 1) ${ }^{48}$ Teniendo en cuenta esta diversidad estructural no es sorprendente que la investigación en el campo de la alelopatía este volcada hoy día hacia el estudio de los factores que pueden afectar la composición del compuestos liberados a través de los exudados, y todas las implicaciones que este hecho significa para la rizósfera ${ }^{171}$ y por tanto, en la naturaleza de las interacciones planta-planta y planta-microorganismos. Este hecho ha adquirido tal importancia, que se ha citado que el estudio cualitativo y cuantitativo de la dinámica de los aleloquímicos liberados al ambiente es crucial para demostrar la hipótesis del fenómeno alelopático. ${ }^{131}$

\section{FACTORES QUE AFECTAN LA COMPOSICIÓN QUÍMICA DE LOS EXUDADOS DE LA RAÍZ}

Debido a la importancia que tienen los compuestos en los exudados se ha señalado que el estudio de la actividad de exudación por una planta, el tipo y destino de los aleloquímicos en el suelo, los cambios que estos provocan sobre la biología y características físicas de la rizósfera, y su absorción por organismos receptores, son elementos fundamentales en el estudio del fenómeno alelopático. Antes de estudiar las actividades biológicas de los compuestos con

Tabla 2. Compuestos orgánicos detectados en exudados de raíz de plantas

\begin{tabular}{|c|c|c|}
\hline Clase & Ejemplos & Función reportada \\
\hline Carbohidratos & $\begin{array}{l}\text { Arabinosa, glucosa, fructuosa, galactosa, maltosa, ramosa, ribosa, } \\
\text { sucrosa y ribosa }\end{array}$ & $\begin{array}{l}\text { Proveer ambiente favorable para el } \\
\text { crecimiento de microorganismo }\end{array}$ \\
\hline Aminoácidos y aminas & $\begin{array}{l}\text { Todos los } 20 \text { aminoácidos proteicos, ácido amino butírico, } \\
\text { homoserina, cistationina y ácido mugineíco }\end{array}$ & Inhibidor de nematodos \\
\hline Ácidos alifáticos & $\begin{array}{l}\text { Fórmico, acético, butírico, propiónico, maleíco, cítrico, isocítrico, } \\
\text { oxálico, fumárico, malónico, succínico, tartárico, oxaloacético, } \\
\text { pirúvico, oxalogutárico, glicólico, chiquímico, acetonico, valerico, } \\
\text { glucónico }\end{array}$ & $\begin{array}{c}\text { Reguladores del crecimiento de la planta y } \\
\text { efecto inhibidor }\end{array}$ \\
\hline Ácidos aromáticos & $\begin{array}{c}\text { p-hidroxibenzoíco, cafeíco, } p \text {-cumárico, ferúlico, gálico, gentísico, } \\
\text { protecatecuico, salicílico, sináptico, siringico }\end{array}$ & $\begin{array}{l}\text { Efecto estimulante, dependiente de la } \\
\text { concentración de prueba }\end{array}$ \\
\hline Fenólicos varios & Flavonoides, flavonas, flavononas, antocianininas, isoflavonoides & $\begin{array}{c}\text { Inhibidor o estimulante del crecimiento } \\
\text { dependiendo de la concentración de prueba }\end{array}$ \\
\hline Ácidos grasos & Linoleíco, linolénico, oleíco, palmítito, esteárico & Reguladores de crecimiento \\
\hline Steroides & Compestrol, colesterol, sitosterol, estigmasterol & Reguladores de crecimiento \\
\hline Enzimas y otros & & Desconcocidos \\
\hline
\end{tabular}



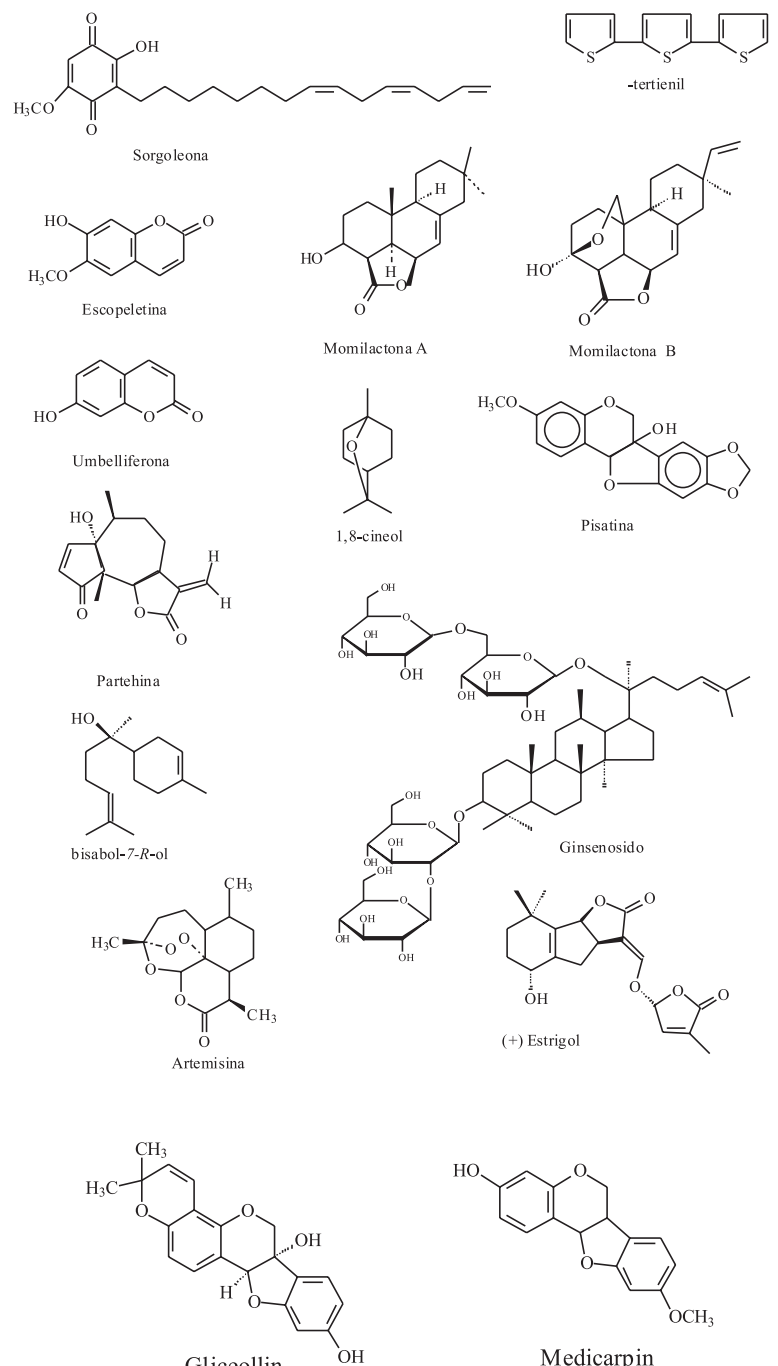

Gliceollin

Medicarpin

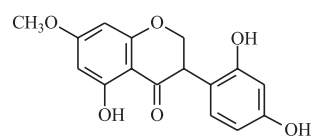

Cajanin

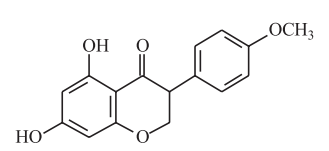

Biochanin A

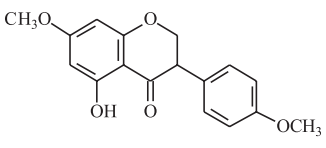

Cajanin

Formononetin<smiles>O=C1Oc2cc(O)ccc2C2Oc3cc(O)ccc3C12</smiles>

Coumestrol

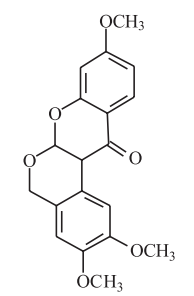

Munduserona

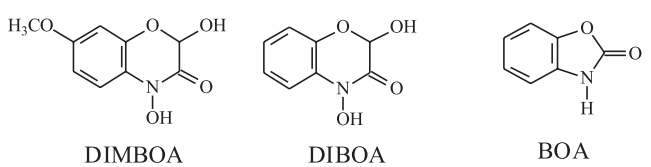

Figura 1. Estructura química de algunos metabolitos secundarios con potencial alelopático identificados en los exudados de la raíz potencial alelopático, es necesario determinar si su planta productora es capaz de liberar al entorno este potencial aleloquímico. También se ha señalado que uno los mecanismos que operan en la planta para lograr una traslocación efectiva al medio de estos aleloquímico es la exudación por raíz, pues es la que involucra tejido vivo, actividades fisiológicas y funciones importantes para el establecimiento de la planta. Desde el punto de vista de las interacciones planta-planta, la idea generalmente aceptada es la interacción directa de un compuesto liberado por una especie de planta donadora A, el cual causa un efecto sobre una planta receptora B (Tabla 1). Sin embrago, siendo el suelo el soporte de las plantas, y zona de tránsito del aleloquímico, éste debe de interaccionar con esta zona durante su tránsito, y dependiendo del tipo de interacción, el aleloquímico, o lo que resulte de esa interacción, logrará una respuesta biológica a la planta codificada como receptora.

Es evidente que las especies químicas liberadas y sus concentraciones relativas, son variables fundamentales que determinaran el grado de afectación que estos puedan causar, con lo cual, convierte a los diferentes factores que afectan a la capacidad de exudación por raíz de compuestos químico, elementos claves en el estudio de la ecología de las interacciones planta-planta. En la Tabla 3 se muestran los diferentes factores que pueden modificar los niveles y tipo de compuestos en los exudados de raíz. Entre otros, la planta misma, así como factores de tipo ambientales, son lo que más afectan el potencial de exudación por la raíz. Según la naturaleza de la planta, se encuentra que la composición y cantidad de compuestos exudados por raíz, dependen marcadamente de la fenología de la planta. Por ejemplo, en el maíz, la cantidad total de compuestos liberados por gramo de peso seco de raíz, disminuyen con el desarrollo de la planta. ${ }^{190} \mathrm{Se}$ ha estimado que estos cambios son una consecuencia de alteraciones en el balance de carbohidratos, aminoácidos y aminas, mientras que el balance de otros compuestos constitutivos, no afectan esta cantidad de compuestos liberados, como lo es el caso de los ácidos orgánicos.

Muchos estudios han sido conducidos para entender esta diferencia en la exudación entre plantas jóvenes y adultas, donde se ha podido demostrar que ciertos rasgos o características fisiológicos, como que la capacidad de distribución de carbono asimilado por raíz hacia el tallo, es un factor fundamental. Sobre esto, se ha observado que la asimilación de carbono desde el medio de crecimiento en plantas jóvenes es traslocado a la raíz, mientras que en plantas adultas, el mismo es traslocado de manera preferencial tallo, ${ }^{191}$ con lo cual, la distribución de carbono entre los diferentes órganos de la planta influirá también en los compuestos orgánicos exudados. Por lo tanto, es importante determinar la acumulación de carbono en la raíz y el tallo, o la acumulación de algunos compuestos en particular, para poder determinar rasgos adaptativos, como el crecimiento de raíz bajo condiciones de estrés y la dinámica de liberación de compuestos orgánicos desde la raíz, pues estos afectan de manera decisiva la biomasa microbial, ciclo de nutrientes y descomposición de materia orgánica. Es decir, describir el comportamiento de los compuestos liberados por la raíz y su importancia para las funciones adaptativas que éstos puedan tener en la planta, debe de incluir el comportamiento durante el desarrollo de la planta. De esta manera es posible describir, al menos para ese grupo de compuestos, cómo es la distribución de carbono invertido en su biosíntesis, y poder tener algún tipo de información sobre la necesidad de la planta a perder carbono liberando estos compuestos a su entorno, o conservar los mismos como reserva de energía y materia para su crecimiento, o su almacenamiento y uso como un mecanismo de defensa de tipo constitutiva.

Este tipo de estudio ha sido considerado recientemente en la dinámica de distribución de algunos aleloquímicos en la planta, que han incluido la velocidad de acumulación durante el desarrollo de la 
Tabla 3. Factores que afectan al proceso de exudación de sustancias por la raíz

\begin{tabular}{lcc}
\hline Variable & Comentario \\
& FACTORES DE LA PLANTA & Ref. \\
\hline
\end{tabular}

Especie y variedad

Considerable variación entre especies, tanto cualitativa como cuantitativa. Mayores variaciones observadas en ácidos orgánicos simples y aminoácidos. Aleloquímicos como ácidos 48,195, 196, 197 hidroxámicos y momilactona también han sido observados a variar con la especie.

Fenología

Altos niveles de concentración en estados tempranos de desarrollo (germinación y plántulas). Rasgo característico en plantas exudando ácidos fenólicos y hidroxámicos.

$48,198,199$

FACTORES AMBIENTALES

Condiciones de cultivo

Condiciones de cultivo afecta la exudación (ejemplo hidropónico vs. soporte sólido de

vidrio). Aumento con la impedancia mecánica. Se supone daños en la superficie de la raíz durante su crecimiento aumentando su exudación.

200, 201, 202

Variable que más afecta los niveles de exudados, aumentando con el suministro de N, P y K,

Nutrientes

aunque algunas deficiencias minerales pueden aumentar el exudado de algunos compuestos, 203, 204, 205, 206 como el aumento de ácidos fenólicos en exudados con la deficiencia de Fe.

$\mathrm{pH}$

Efecto difícil de predecir por lo dinámico de los procesos en la interfase raíz-suelo. El trigo se observa un aumento en los exudados con disminución del pH (de 6,4 a 5,9). Los mismos exudados pueden modificar el $\mathrm{pH}$ de la rizosfera.

planta. Así, se ha estudiado la acumulación de DIBOA en 10 cultivos de centeno bajo diferentes regímenes de fertilización y etapas de desarrollo. ${ }^{40}$ Se encontró una disminución del contenido del aleloquímico durante el desarrollo de la planta, donde la disponibilidad de nitrógeno no influyo en los niveles de DIBOA acumulados. Otro estudio sobre la misma planta, fue un poco más detallado, donde se determinó el contenido de DIBOA, tanto en tallo como en raíz, durante su desarrollo, ${ }^{192}$ encontrándose que la relación (raíz/tallo) de DIBOA no cambia considerablemente en las plantas jóvenes (plántulas). Un comportamiento similar ha sido observado para DIMBOA en plántulas de trigo ${ }^{193}$ y maíz. ${ }^{194}$

En algunos trabajos se han realizado correlaciones entre estas concentraciones de los aleloquímico en la planta entera y la cantidad que ésta puede exudar. Por ejemplo, se ha estudiado la correlación entre Momilactona B, un potente aleloquímico aislado de exudados de raíz de plántulas de arroz, ${ }^{125}$ con los registrados en la plántula, donde una relación directa en el contenido endógeno existe con los exógenos, done concluyen que existe una dependencia entre la concentración del aleloquímico endógeno y la cantidad liberada por exudación. Sin embargo, el estudio no se efectuó durante todo el desarrollo de la planta, sólo realizando las determinaciones a 15 días de crecimiento contados desde su germinación, lo cual representa solo una situación puntual, por lo que es necesario el registro durante varios estadios de crecimiento para llegar a una conclusión definitiva. En otro estudio si incluyo la concentración de éste en la raíz, el tallo y el exudado, ${ }^{121}$ y las medidas realizadas después de 10 días de crecimiento, donde se demostró que la menor cantidad de aleloquímico en la planta es localizado en la raíz. Sin embargo, este tipo de correlación directa entre los aleloquímicos registrados en planta y los niveles registrados en los exudados, no es un comportamiento generalizado, encontrándose algunos resultados no concluyentes. En el caso de trigo, se ha observado que no existe correlación entre los niveles de aleloquímicos (DIMBOA y ácidos fenólicos principalmente) en exudados y los registrados en la planta, donde se sugiere que parte de los aleloquímico son retenidos por la planta una vez sintetizados. Estos resultados demuestran la necesidad de estudiar la distribución de los aleloquímicos en todo el sistema planta, donde se registre de una manera dinámica, los niveles en tallo, raíz y sus exudados. La correlación existente entre la planta y los niveles liberados, no sólo podrá describir la traslocación y localización preferencial de los compuestos, sino que podría definir el potencial alelopático de diferentes especies, puesto que a pesar de que una especie pueda concentrar en su tejido elevadas cantidades de aleloquímico, es posible que el mismo no sea exudado al medio de crecimiento. Como también se puede observar en la Tabla 3, otros factores propios del ecosistema juegan un papel importante en la capacidad de exudar compuesto, donde los factores ambientales pueden alejarse de las condiciones óptimas de crecimiento de la planta, originando estrés, que cursa con condiciones que afectan de manera importante el crecimiento y desarrollo de las plantas y cualquier otro organismo, ${ }^{224}$ el cuál puede ser clasificado, según su naturaleza, como biótico y abiótico.

El estrés abiótico se puede producido por niveles inapropiados de componentes físicos del ambiente, como temperatura, niveles de $\mathrm{CO}_{2}$, radiación solar, etc., mientras que el estrés biótico es causado por la presencia de patógenos, parásitos, depredadores y otros organismos competidores del espacio y los nutrientes. La capacidad de un organismo a sobrevivir y recuperarse de condiciones desfavorables, dependerá de sus mecanismos básicos, o adquiridos evolutivamente, para tolerar tal estrés. Según la característica del estrés, las plantas responderán resistiendo al estrés, mediante algún mecanismo de resistencia que le permite el normal desarrollo bajo las condiciones de estrés, o en el peor de los casos, con una inoperatividad de mecanismo, morir como consecuencia del daño causado por el estrés.

Por ejemplo, si las plantas son sometidas a altas temperaturas, pero sin ser letales para su funcionamiento, éstas desarrollaran tolerancia y sobrevivir a tales temperaturas, que en condiciones de desarrollo de no estrés serían letales. ${ }^{225}$ Por el contrario, si el grado de tolerancia y resistencias no son lo suficientemente efectivas frente al estrés, estas sencillamente morirían, desapareciendo del ecosistema, y evolutivamente estas plantas estarían restringidas a un hábitat que presente niveles de parámetros de estrés a valores mucho menores a aquellos considerados letales, y los cambios adaptativos serán mayor o menor eficiencia, mientras menos exigidos sean, es decir, mientras que el estrés a que están sometidos, aunque sean condiciones desfavorables, estén por debajo de los niveles letales.

Muchos de estos mecanismos comprenden respuestas tanto morfológicas como químicas de la planta, siendo los metabolitos secundarios los constituyentes principales de respuesta de las plantas a estrés de tipo ambiental, y como resultado, la planta es capaz de modificar su química secundaria, siendo la variabilidad de esta química dependiente de la naturaleza y grado del estrés.

Aunque la mayor parte de las modificaciones químicas producidas 
por estrés ambiental suceden básicamente en las partes aéreas de las plantas, que es la más expuesta a muchos tipos de estrés; como la radiación y la herbívoría, las variaciones químicas de éstas pueden ser transmitidas a sus partes subterráneas. Las investigaciones en las interacciones planta-planta, y específicamente aquella mediadas por químicos, están siendo orientadas en el estudio del efecto de las modificaciones de la química secundaria y el efecto que esto produces sobre estas interacciones. Teniendo en cuenta que en este tipo de interacciones los exudados por raíz han sido citados como un elemento clave, los estudios han sido orientados hacia el efecto de diferentes variables del ambiente sobre la acumulación de aleloquímicos en la planta y su liberación mediante exudado de raíz. Así, algunas plantas han sido estudiadas en relación a su capacidad de acumular aleloquímicos bajo diferentes condiciones de estrés, como lo es el efecto de la temperatura y fotoperiodo, ${ }^{226,227}$ la defoliación, ${ }^{228-}$ ${ }^{230}$ la fertilización, ${ }^{231}$ la herbívoría, ${ }^{232}$ la sequedad ${ }^{233}$ y la concentración de aniones. ${ }^{234,235}$

Entre estos estudios, algunos citan que el aumento de la exposición a luz visible en plántulas de maíz, causa un aumento de los niveles de DIBOA tanto endógeno como exógenos (exudados de raíz), ${ }^{228-230}$ onde los ensayos fitotóxicos indican que existe un aumento en el potencial alelopático de la planta frente a este tipo de condición de estrés físico. El fenómeno de daño físico a las partes aéreas también ha registrado efectos sobre los niveles de aleloquímicos en la planta. Para centeno se encuentra que los niveles de DIBOA medidos en el tallo son mayores en las plantas tratadas (defoliación mecánica), aumentado también los niveles de este aleloquímico en los exudados de sus raíces. Para el maíz no se encuentran diferencias entre el contenido de DIMBOA en los niveles de aleloquímicos entre raíz y exudados, solo mostrando diferencia significativa el contenido en tallo. Esto resultados indican que la respuesta a defoliación no es generalizada respecto a la acumulación y liberación de aleloquímicos, siendo dependiente de la especie de planta y de otras variables como su etapa de crecimiento.

Otros tipo de estudios sobre estrés y respuesta de la planta, han incluido la infección controlada con insectos, en especial áfidos, una familia de insectos que poseen un sistema de alimentación muy especializados, penetrando la epidermis y capa mesofílica de las plantas en busca de lugares específicos de reservorio de alimentos, y representan una de las principales plagas que sufren los cultivos de trigo, maíz y centeno. ${ }^{236}$ Los estudios de la infestación con áfidos a plantas de trigo han mostrado que existe respuesta en el tipo de compuestos que pueden ser detectados en sus partes aéreas (defensa inducida), ${ }^{237}$ principalmente compuestos volátiles. Sin embrago, este tipo de respuesta de las plantas en la inducción de compuestos volátiles, se ha propuesto que el tipo de información, y así el tipo de respuesta, puede ser transmitido por la rizósfera, ${ }^{238}$ con lo cual, se ha planteado que la infección por áfidos en ciertas plantas, puede causar cambios importantes en la química secundaria destinada a la defensa contra la infección de estos insectos.

Así, se ha demostrado que algunos aleloquímicos propios de estas plantas, como los ácidos hidroxámicos, son activos frente a este tipo de infección por áfidos. ${ }^{239,240}$ Los resultados en los cambios de los niveles de estos compuestos son muy similares a los encontrados mediante estrés por defoliación; registrándose un aumento de los niveles de ácidos hidroxámicos en plantas de trigo expuesta a la infección por áfidos, ${ }^{241}$ donde existen muchas variables experimentales tales como número y tipo de hoja infectada, tiempo de infestación, fenología de la planta, etc., que hace difícil llegar a conclusiones en el estudio.

No existen estudios sobre el efecto de este estrés y la respuesta de exudación de los compuestos involucrados como defensa. Desde el punto de vista de interacción de la planta con su entorno, y la respuesta de ésta al estrés que el ecosistema puede causar a la mis- ma, sin duda que uno de los factores más importante de la ecología de las plantas es la presencia de microorganismo en el suelo donde la planta se desarrolla. En el suelo, la planta debe de interaccionar con todo lo animado que ella contiene, donde se incluyen bacterias, hongos, protozoarios, artrópodos, nemátodos y helmintos, que, en conjunto, son los encargados de los procesos de descomposición, mineralización, ciclo de nitrógeno y carbono, almacenar y liberar nutrientes, entre otras funciones.

A pesar de que no existen suficientes datos en la literatura para llegar a una conclusión definitiva, los resultados hasta ahora obtenidos apuntan a que la presencia de microorganismo aumenta significativamente los niveles de exudados. ${ }^{5}$ Existen varias hipótesis para explicar este hecho. Una de estas plantea que en un medio no estéril, las raíces pueden establecer simbiosis con hongos micorricicos, tanto endotróficos o dentro de la raíz, o exotróficos (interface raíz-rizósfera), formando una envoltura para el esqueleto del sistema radicular. Se estima que este tipo de simbiosis facilita hasta un $30 \%$ la capacidad de asimilación de nutrientes y su foto asimilación de la planta, ${ }^{242}$ aumentando de esta manera la síntesis y exudación de compuestos de rutas secundarias. Por otro lado, para aquellos microorganismos no simbióticos, se estima que estos capturan y asimilan compuestos de bajo peso molecular liberados pasivamente desde la raíz, y de aquí, estos mantienen un gradiente de carbono entre el tejido interno de la raíz y la solución de suelo, contribuyendo al flujo de compuesto desde el interior al exterior de la raíz. Sumado a esto, la micro flora del suelo puede sintetizar enzimas o metabolitos que pueden alterar la integridad de las células de la raíz, o la permeabilidad de sus membranas, modificando sus funciones normales de exudación. ${ }^{243}$ En general se considera que los exudados de raíz son modificados por la presencia de estos organismos en el suelo, tanto cualitativamente como cuantitativamente. Transformaciones químicas de tipo biológicas y factores físicos, como adsorción irreversible, formación de complejos y dilución en la solución de suelo, afectan además los niveles de concentración, jugando un papel fundamental en los efectos que estos compuestos liberados puedan ejercer sobre otros organismos. Al mismo tiempo, se estima que la composición y concentración de los compuestos en los exudados, son fundamentales en la ecología de los sistemas vivos involucrados en la rizósfera, como mortalidad y niveles poblacionales de las colonias formadas, sin embargo, existen datos contradictorios, ${ }^{244,245}$ de donde nace la necesidad de estudiar todos los factores involucrados, tanto en los exudados de raíz, como sus modificaciones cualitativa y cuantitativas, además de los efectos que estos puedan causar en el micro y macro ambiente de la planta. Son los resultados de estos estudios los que determinaran el verdadero potencial alelopático de la planta, y elucidar el compuesto y su nivel de concentración verdaderamente activo.

\section{ANÁLISIS DE LOS ALELOQUÍMICOS EN LOS EXUDADOS DE LA RAÍZ}

Como se ha descrito, el fenómeno de exudación por la raíz de compuestos alelopático ha sido intensamente estudiado durante muchos años, siendo a partir de los años setenta, donde se registra el inicio de una intensa actividad investigativa, aumentando progresivamente con los años el número de registros sobre el tema, lo que demuestra la importancia del fenómeno de exudación tanto en la ecología de las plantas, como la influencia que este puede tener en la biótica del suelo. A pesar de que en los estudios en el campo de la alelopatía se han postulado los diferentes mecanismos de liberación de aleloquímicos, los estudios iníciales relacionados con la medida del potencial alelopático de planta, fueron dirigidos al aislamiento, elucidación estructural y medidas de las actividades de compuestos 
obtenidos a partir del procesamiento del material vegetal. Los estudios se centraban en la búsqueda de compuestos de naturaleza secundaria, a los cuales se les medía su bioactividad mediante diferentes pruebas y diseños de los bioensayos. ${ }^{246-248}$ Sin embargo, debido a la importancia del fenómeno de exudación en este campo de la ecología, y al avance de técnicas de análisis de metabolitos secundarios, los estudios del fenómeno de exudación han aumentado significativamente. A partir de finales de los años 90, se registra un incremento en los estudios de exudados de raíz y su implicación en el fenómeno de la alelopatía (Figura 2). Este interés va más allá de la función de la raíz como vía de transmisión del aleloquímico hacia el suelo, sino como un órgano capaz de expresar su propia capacidad sintética, al poder sintetizar y almacenar metabolitos secundarios. ${ }^{249}$

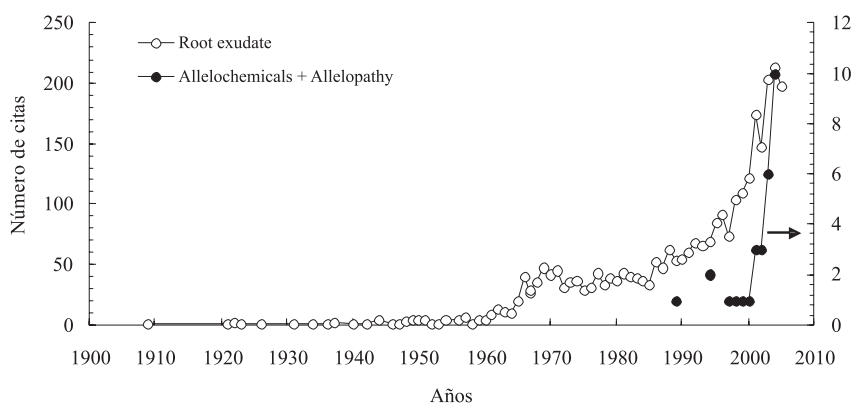

Figura 2. Número de trabajos sobre el fenómeno de exudación por la raíz y el número de trabajos relacionados con el fenómeno alelopático. Motor de búsqueda: SciFinder Scholar 2007. Claves de búsqueda: Root exudate. Root exudate + allelopathy + allelochemical

Durante el estudio del fenómeno de exudados por raíz, se ha determinado que mucho de los compuestos liberados son sintetizados directamente en la raíz (Tabla 4), lo cual despertó la relevancia que este hecho sobre las diferentes variables encontradas al estudiar la ecología de las plantas. Las raíces pueden producir metabolitos secundarios que son directamente exudados al ambiente, sin que los mismos puedan ser detectados en las partes aéreas. Es tal esta especificidad de síntesis, que muchos compuestos con actividades biológicas relevantes han sido localizados casi de manera exclusiva en este órgano. Por ejemplo, los ácidos hidroxámicos y sus derivados,

Tabla 4. Algunos grupos de metabolitos secundarios sintetizados y almacenados en la raíz

\begin{tabular}{lcc}
\hline Planta & Metabolito & Ref. \\
\hline Ajuga reptans var. atropurpurea & 20-hidroxiecdisona & 250 \\
Armoracia rusticana & Fusicoccin & 251 \\
Artemisia annua & Artemisina & 252 \\
Echinaceae purpurea & Alcamidas & 253 \\
Lithospermum erythrorhizon & Naftoquinonas (Shiconin) & 254 \\
Lobelia cardinalis & Poliacetilenos & 255 \\
Rauwolfia serpentina & Alcaloides indol & 256 \\
Rubia tinctorum & Antraquinonas & 257 \\
Salvia miltiorrhiza & Diterpenoides & 258 \\
Serratula tictoria & Ecdisteroides & 259 \\
Trichosanthes & Ácido brillonólico & 260 \\
Valeriana officinalis var. & Diestes iridois & 261 \\
sambucifolia & & \\
\hline
\end{tabular}

con actividades biológicas ampliamente referenciadas, se encuentran distribuidos en tallo y raíces de plantas como el trigo, el maíz y el centeno; sin embargo, en algunas plantas, como las pertenecientes a las Acanthaceae, con más de 2500 especies entre zonas tropicales y subtropicales, se han encontrado que éstos compuestos son detectados casi de manera exclusiva en sus raíces. ${ }^{262-264}$

Estos antecedentes, así como la búsqueda de una evaluación más realista del potencial alelopático de las plantas, han dado origen a un intenso estudio de los exudados de raíz, los compuestos presentes en éstos, y su asociación con los efectos biológicos. Así, muchos metabolitos secundarios han sido detectados en exudados de diferentes especies plantas con propiedades alelopáticas, siendo muy variadas y complejas las estructuras de los compuestos identificados (Tabla 5). Muchos estudios han demostrado que las actividades fitotóxicas se correlacionan con los niveles de algunos de estos compuestos en sus exudados y que estos pudieran ser responsables de los efectos a nivel de campo, soportando la hipótesis de que la toxina liberada al ambiente y tomada por una especie receptora, son requerimientos básicos en la demostración de la existencia del fenómeno de alelopatía. ${ }^{267}$ Conociendo la necesidad de medir los exudados de raíz, estudiar su contenido de aleloquímicos, y diseñar bioensayos para medir el potencial alelopático, ha sido tema de estudio durante los últimos años, donde se han desarrollado metodologías para medir la actividad fitotóxica de los exudados en co cultivos de especie donadora y receptora, que permita al mismo tiempo el análisis del contenido de algunos compuestos de sus exudados. ${ }^{284} \mathrm{~A}$ pesar de estos intentos de desarrollar metodología estándares para medir tanto el potencial alelopático así como los efectos de exudados de raíz, existen muchas variaciones en las metodologías empleadas para el análisis de exudados de raíz. Como se muestra en la Tabla 5, de manera general, se utilizan medios hidropónicos para mantener las plantas y los exudados son analizados de manera directa de la solución de cultivos. En algunos casos se usan soporte sólido; como perlitas de vidrio, cuarzo, arena o agar para mantener los cultivos. Dependiendo de los niveles de concentración en que los compuestos pueden encontrase en la solución de cultivo, algunas unidades de preconcentración han sido empleadas, como amberlita (XAD-4 y XAD-8) y adsorbentes para compuestos poco polares, como los absorbentes sólido de fase inversa C-18. Una fase con la propiedad de absorber selectivamente analitos pocos polares, empleados rutinariamente en cromatografía líquida. En estas, la solución de cultivo es recirculada a través de trampas conteniendo las resinas o soportes selectivos, siendo eluidos posteriormente con metanol, y los compuestos adsorbidos son identificados por los métodos analíticos estándares. ${ }^{285}$ Este sistema permite la colección de los exudados de una manera próxima a las condiciones naturales de liberación y/o exudación, con la mínima perturbación del sistema radicular de la planta (daño celular). Permite además el análisis de compuestos que son exudados a muy bajas concentraciones, que en otras condiciones sería necesario el manejo de un gran número de plantas y períodos de recolección prolongados. Además se evitaban los tediosos procedimientos de toma y procesamiento de grandes cantidades de solución, que algunas veces conllevaban a modificación de los compuestos exudados (artefactos), además de minimizar los problemas de contaminación de todo el sistema (medio de crecimiento, contenedores, solución nutriente, etc.). Este sistema ha sido modificado mediante la inclusión de un segundo reservorio, donde se encuentra la solución nutritiva. ${ }^{286}$ Utilizando este modelo, se han desarrollado otros sistemas, el cual permite no solo la recolección de exudados, sino el control del volumen de solución nutritiva aplicado a las especies de estudios, así como un análisis en serie, que facilita la realización de replicas de manera simultánea, o la realización de estudios dosis respuesta. ${ }^{286}$ Actualmente los estudios están orientados a la medida de los niveles de exudados en la rizósfera 
Tabla 5. Condiciones experimentales para la captura y análisis de compuestos potencialmente alelopáticos en los exudados de la raíz

\begin{tabular}{|c|c|c|c|c|c|}
\hline \multirow{2}{*}{ Planta } & \multicolumn{2}{|c|}{ Crecimiento } & \multirow{2}{*}{ Aleloquímico } & \multirow{2}{*}{ Captura $\zeta$} & \multirow{2}{*}{ Ref } \\
\hline & Soporte* & Condiciones** & & & \\
\hline Oryza sativa $\mathrm{L}$ & $\mathrm{H}$ & $\mathrm{NE}$ & Momilactona B & XAD-8 & 122 \\
\hline Acroptilon repens & $\mathrm{H}$ & NE/ES & 7,8-Benzoflavona & $\mathrm{AD}$ & 265 \\
\hline Agropyron repens & $\mathrm{H}$ & $\mathrm{NE}$ & DIMBOA & $\mathrm{AD}$ & 266 \\
\hline Avena fatua & $\mathrm{H}$ & NE & Escopeletin & $\mathrm{AD}$ & 269 \\
\hline Avena fatua & $\mathrm{S}$ & $\mathrm{NE}$ & Escopeletin & $\mathrm{AD}$ & 270 \\
\hline Brassica alba & $\mathrm{H}$ & $\mathrm{NE}$ & 3,5,6,7,8-pentahidroxi flavona & $\mathrm{AD}$ & 273 \\
\hline Centaura maculosa & $\mathrm{S}$ & $\mathrm{NE}$ & $( \pm)$-Catequin & $\mathrm{AD}$ & 277 \\
\hline Desmodium uncinatum & $\mathrm{H}$ & $\mathrm{NE}$ & $\begin{array}{c}\text { 5,7,2',4'-tetrahidroxi-6-(3-metilbut-2-enil)iso } \\
\text { flavanona }\end{array}$ & C-18 & 275 \\
\hline Diplachne fusca (linn.) beauv & $\mathrm{H}$ & $\mathrm{E}$ & Ácido málico y fumárico & $\mathrm{AD}$ & 281 \\
\hline Dittrichia viscosa & $\mathrm{H} / \mathrm{Q}$ & $\mathrm{NE}$ & Fenólicos & $\mathrm{AD}$ & 279 \\
\hline Eichhornia crassipes & $\mathrm{H}$ & $\mathrm{E}$ & $\begin{array}{l}\text { N-fenil-1-naftilamina } \\
\text { N-fenil-2-naftilamina }\end{array}$ & $\mathrm{AD}$ & 267 \\
\hline Leonurus sibiricus $L$. & $H$ & $N E$ & Acido cafeíco & $A D$ & 278 \\
\hline Oryza sativa $L$ & $H$ & $E$ & Momilactona $B$ & $A D$ & 126 \\
\hline Oryza sativa $\mathrm{L}$ & $\mathrm{H}$ & $\mathrm{E}$ & Momilactona B & $\mathrm{AD}$ & 126 \\
\hline Oryza sativa $\mathrm{L}$ & SS & NE & $\begin{array}{l}\text { Ácidos 5-hidroxi-2-indolecarboxlico y } \\
\text { 5-hidroxiindole-3-acetico }\end{array}$ & $\mathrm{AD}$ & 196 \\
\hline Oryza sativa $L$ & $H$ & $N E$ & Momilactona $B$ & $X A D-8$ & 122 \\
\hline Oxalis tuberosa $\mathrm{L}$. & $\mathrm{H}$ & $\mathrm{NE}$ & Harmina/Hermalin & $\mathrm{AD}$ & 276 \\
\hline Phaseolus vulgaris & $\mathrm{H} / \mathrm{Q}$ & $\mathrm{NE}$ & Ácidos orgánicos & $\mathrm{AD}$ & 280 \\
\hline Zea mays L. & $\mathrm{V}$ & $\mathrm{NE}$ & (6R)-7,8-Dihidro-3-oxo- $\alpha$-ionona & $\mathrm{AD}$ & 274 \\
\hline Picea abies & $\mathrm{P}$ & $\mathrm{E}$ & Ácido oxálico y fórmico & $\mathrm{AD}$ & 272 \\
\hline Polygonum sachalinense & $\mathrm{H}$ & $\mathrm{NE}$ & Emodin & $\mathrm{AD}$ & 268 \\
\hline Secale sereale L. & $\mathrm{V}$ & $\mathrm{NE}$ & DIBOA & $\mathrm{AD}$ & 54 \\
\hline $\begin{array}{l}\text { Secale cereale y Triticum } \\
\text { aestivum }\end{array}$ & $\mathrm{H}$ & NE/ES & DIMBOA/DIBOA & XAD-4 & 53 \\
\hline Solanum abutiloides & $\mathrm{V}$ & $\mathrm{NE}$ & 3-hidroxisolavetivone & $\mathrm{AD}$ & 271 \\
\hline Sorghum bicolor & $\mathrm{H}$ & $\mathrm{NE}$ & Sorgoleone & $\mathrm{AD}$ & 283 \\
\hline Triticum aestivum $L$ & SSS & $\mathrm{E}$ & DIMBOA & $\mathrm{AD}$ & 179 \\
\hline Zea mays L. & Q & $\mathrm{E}$ & HMBOA & $\mathrm{AD}$ & 282 \\
\hline
\end{tabular}

H: Hidropónico. S: Sólido (Arena) SS: Soporte Sólido: SSS: Soporte semisólido (AGAR). V: vermiculita. P: Pelitas de vidrio. Q: Cuarzo.

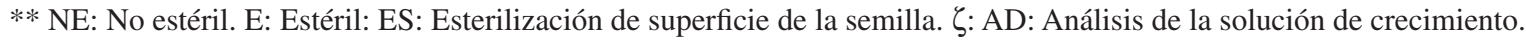

en suelo, lo que ha llevado a la utilización de otros materiales con propiedades a los resinas y adsorbentes, como polidimetilsiloxano $\left[\left(\mathrm{OSiMe}_{2}\right)_{\mathrm{n}}\right]$, que ha originado buenos resultados, incluso mejor que los adsorbentes comúnmente aplicados para este fin, como C-18, XAD-7. ${ }^{171}$ En términos generales, todos los sistemas son similares entre sí, y todos buscan un objetivo, tratar de detectar y dar identidad estructural a la mayor cantidad de compuestos en los exudados, y correlacionar los niveles de éstos con las actividades biológicas medidas con estos exudados de raíz. Es decir, tratar de caracterizar lo más minuciosamente los rasgos funcionales de los exudados de las raíces en su interacción con la rizósfera de la planta. Fenómenos como interacción microbiana, adquisición de nutrientes y adaptación de la planta a estrés ambientales o condiciones adversas de la química del suelo, son hoy día temas de intensa investigación, no sólo desde el punto de vista de investigación básica, sino en lo relativo a los aspectos prácticos que esta puedan generar, por ejemplo, aquellos asociados a los manejos de cultivo y la búsqueda de estructuras novedosas que sirvan de moléculas dianas en el desarrollo de herbicidas. Desde un punto de vista metodológico, existe la necesidad de una re evaluación cualitativa y cuantitativamente de estas técnicas para evaluar la recolección de exudados de raíz y de sus resultados experimentales, principalmente a la luz de recientes hallazgos que demuestran una variación espacial de la liberación de exudados en la arquitectura de la raíz, ${ }^{287-290}$ además del fuerte efecto que ejerce parámetros como la impedancia mecánica del medio de crecimiento, ${ }^{291}$ lesión en la raíz ${ }^{292,293}$ dinámica microbiana en la rizósfera y la adsorción de exudados sobre la matriz suelo y su efecto sobre la recuperación y medida de los compuestos orgánicos presentes en éste. ${ }^{171}$

Por otro lado, desde un punto de vista de la biología de la planta, y entendiendo el proceso de exudación como uno de los factores 
que rige la distribución poblacional de las plantas en un ecosistema, muchas investigaciones están dirigidas a aumentar la capacidad de exudación por la raíz de compuestos con actividades biológicas, en especial en plantas con interés económico. Los efectos esperados de un aumento en la capacidad de exudación de compuestos por la raíz, es de aumentar la competitividad de la planta, de tal manera que el resultado sea un mejor manejo de cosechas, como por ejemplo, una disminución en el uso de herbicidas basados en fósforo, así como proveer a la planta de una mayor tolerancia al estrés de aluminio (III) en el manejo de suelo ácidos, ${ }^{294}$ rasgos éstos alcanzados maximizando la función de exudación por la raíz.

En este sentido, las plantas poliploides han sido observadas con gran interés, y los resultados hasta ahora muestra que estas han ofrecido ventajas importantes en la agricultura, ${ }^{295}$ y son frecuentemente consideradas superiores a las diploides respecto a su adaptabilidad genética y tolerancia a estrés ambiental. ${ }^{296,297}$ Por otra parte, en áreas como la horticultura ornamental, las plantas poliploides son extensamente usadas por su mejor características ornamental, tales como flores más grandes e incremento de algunos rasgos adaptativos, como la tolerancia al frío, ${ }^{298}$ déficit de agua ${ }^{299}$ y poseer mayor capacidad fotosintética ${ }^{300}$ En el caso de plantas medicinales, la inducción de poliploide puede ser útil para incrementar la producción de compuestos medicinales (metabolitos secundarios) importantes a partir de muchas plantas, comparada con su parental diploide..$^{301-305}$ Sin embargo, los efectos fisiológicos de la generación de poliploides en general, son impredecibles y dependiente de la especie ${ }^{306}$ lo cual evidencia la prevaleciente necesidad de estudiar cada especie en relación a éste aumento en la producción metabolitos secundarios, así como todas las características morfológicas y ecológicas como consecuencia de esta poliploidismo inducido. ${ }^{306}$ A pesar de que existen antecedentes de estudios sobre el incremento de la producción de metabolitos secundarios mediante la inducción de poliploides, no existen datos sobre el efecto que esto causa sobre los niveles de exudación de compuestos a través de la raíz. Partiendo del hecho de que el control genético de la exudación por raíz está siendo estudiado desde el punto de vista de generar mejor rendimiento y manejo de las plantas de interés agronómico, el estudio del efecto de la inducción de poliploides es importante, no sólo por el efecto que este pueda producir de los niveles de aleloquímicos en planta y en sus exudados, sino porque puede generar diversos genotipos para los programas de cultivo (Breeding) en la búsqueda de los marcadores genéticos que gobiernen la producción y exudación de agentes alelopáticos. ${ }^{307}$

Como se puede observar, los niveles de aleloquímicos medidos han sido llevados a cabo en diferentes condiciones de cultivo y de crecimiento, donde se usan diversos soportes de cultivo y diferente grado de esterilidad de los sistemas. Teniendo en cuenta los antecedentes de los factores que afectan la capacidad de exudación de compuestos orgánicos por la raíz, es posible que cada uno de estas variables sea un factor que puede modular y fijar las actividades biológicas medidas a partir de estos exudados. En este sentido, los objetivos a seguir están orientados a estudiar como la dureza de los diferentes soportes de crecimiento pueden influir en los niveles de aleloquímicos presentes en exudados de raíz. Siendo muchos de los aleloquímico muy sensibles a transformaciones, tanto espontánea como catalizada por microorganismo, es necesario considerar el efecto de las condiciones de esterilidad del sistema, dentro de los factores a considerar de tipo metodológico aplicado en los bioensayos; y dentro de los factores de la planta, está el estudio del efecto de la poliploidización inducida en los niveles de aleloquímicos producidos y liberados por las plantas en sus exudados.

\section{LOS EXUDADOS DE LA RAÍZ Y LA RIZO INTERACCION}

Los microorganismo en el suelo se consideran uno de los reservorios de biodiversidad mas grande del mundo, ${ }^{308}$ donde el número de tipo de especies de microorganismos pueden alcanzar valores de $10^{3}$ y $10^{4},{ }^{308}$ con poblaciones de individuos entre $10^{10}$ a $10^{12}$ microorganismos g ${ }^{-1}$ de suelo. ${ }^{309}$ Con esta elevada actividad biológica, no es sorprendente que estos microorganismos sean considerados como una variable crucial en el funcionamiento de un ecosistema y los diversos fenómenos que en el operan. Es por ello, que en el estudio del fenómeno alelopático, los procesos que ocurren en la rizósfera estén siendo revisados en la búsqueda de un mejor entendimiento del fenómeno. Una de las fuerzas selectivas cruciales que afectan la dinámica en la población microbiana en el suelo, lo representan todos aquellos compuestos químicos que pueden ser excretados por las raíces de las plantas, o rizodeposición, implementandoce de esta manera una interacción entre los microorganismos con la rizósfera contentiva de los compuestos químicos en los exudados, o rizointeracción. Por otra parte, es la comunidad microbiana en la rizósfera la que determinara en última instancia, la dinámica poblacional de la vegetación que ella soporta. Así, el proceso de exudación esta siendo estudiado en la búsqueda de los efectos que este causa en la población microbial en la rizósfera.

En general, para su asociación en un ambiente, las plantas dependen de la capacidad de las raíces a comunicarse con los diferentes entes biológicos de la rizósfera; y desde luego, lo inverso es también válido, donde muchas bacterias y hongos son dependientes del alcance de esta asociación con las plantas, y que dicha asociación es función de los agentes químicos en los exudados de la raíz; principalmente aquellos compuestos antimicrobiales inducidos y acumulados en la raíz. ${ }^{310}$ De esta manera, los diferentes interacciones que pueden presentarse entre los entes bióticos en la rizósfera y las plantas es muy compleja, donde, en el caso más simple, los compuestos químicos liberados por las raíces de las plantas, pueden interaccionar de manera directa con cada uno de los diferentes microorganismos presentes en la rizósfera. En estos casos, donde existe una interacción directa, es seguro que los compuestos químicos que esta pueda excretar son los responsables directos del tipo de interacción y efecto causado. Sin embargo, la interacción puede ser más compleja, pudiendo ser una consecuencia de la participación de otros organismos, generando una matriz de variables que regulan la interacción, a tal extrema que existe un solapamiento del lenguaje químico usado. Por ejemplo, las moléculas que en principio son usados como polinizadores, dispersores de semillas y herbívoros; están estructuralmente relacionadas con aquellas que atraen o repelen patógenos o microbios subterráneos mutualistas. ${ }^{311}$ Es decir, muchos bacterias de la rizósfera, como Bradyrhizobium japonicum, con características mutualista con su hospedera, y el patógeno Phytophthora sojae, responde de manera similar a la liberación de isoflavonas mediante exudados de la raíz de la soja. ${ }^{311}$

De esta manera, las interacciones que se producen de manera indirecta entre las plantas y su entorno, son complejas, principalmente a la intervención de los microorganismos o entes bióticos en la rizósfera. De esta manera, entender las diferentes acciones que los exudados pueden producir en la rizósfera es de importancia relevante para dilucidar las causas de loas patrones poblacionales de las especies de plantas, y es en este sentido, donde se han estado estudiando los exudados de la raíz. Desde el punto de vista del papel que los exudados de la raíz podrían juegan en la rizósfera, los efectos han sido clasificados como directos, los que incluyen efectos antimicrobiales, ${ }^{312}$ efectos sobre la lactona $\mathrm{N}$-acilhomoserina, una bacteria encargada de la comunicación célula-célula, y así, de la expresión de gen en una población de bacteria, ${ }^{313}$ simbiosis, ${ }^{314}$ y problemas de adaptación. ${ }^{315}$ Efectos indirectos lo representan básicamente el biocontrol de bacterias por parte de la planta productoras de los exudados de la raíz, ${ }^{316}$ y el biocontrol de hongos. ${ }^{317}$

Entre los efectos distinguidos, el más estudiado ha sido la ac- 
tividad antimicrobial, debido principalmente a la gran diversidad de compuestos con actividad antimicrobial identificados en los exudados de la raíz, donde un sin números de señales pueden ser enviadas a la rizósfera y su biótica; done el compuesto es acumulado principalmente en torno a la raíz. ${ }^{312}$ Se estima que en general las familias de plantas emplean metabolitos secundarios para propósitos similares. Por ejemplo, la mayoría dentro de la familia Leguminosae usan isoflavonoides como agentes antimicrobiales, mientras que los miembros de la Soalnaceae generalmente usan sesquiterpenos para tal fin. Por ejemplo, dentro de las leguminosas, Glycine max produce gliceollin, Vigna unguiculata produce medicarpin, Mundulea seica produce munduserona, Phaseolus vulgaris produce coumestrol y Cajanus cajan produce el cajanin, todos estos compuestos son isoflavonoides que actúan como fitoalexinas en la rizósfera. ${ }^{318}$ Por otra parte, la mayoría de los compuestos en los exudados de la raíz, pueden tener una doble acción, actuando tanto como agentes antibacteriales así como antifúngicos, los cuales actúan regularmente de manera sinérgicas para alcanzar un resultado antimicrobial. ${ }^{312}$ Seguido a esta función antibacterial, muchos metabolitos secundarios en los exudados de la raíz han sido asociados a efectos simbióticos entre plantas y hospederos o relaciones simbióticas en general en la rizósfera. Los metabolitos secundarios que más han sido asociados a este tipo de relaciones son los de tipo fenólicos sencillos y flavonoides. Por ejemplo, en los exudados de la semillas y de la raíces de las leguminosas, se encuentran flavonoides, ácido aldónico y betaínas, los cuales funcionan como transmisores de señales muy sensitivas y específicas, cuya acción es dependiente del simbionte, especie hospedera y los compuestos en sus exudados. La acción según estas variables, puede ser de inhibición de germinación de esporas, formación de nódulos o crecimiento de hongos. ${ }^{318}$ Por ejemplo, biochanina A y formononetina, cuando son producidas por Trifolium repens, han sido asociados a efectos estimulantes del crecimiento de hongos, pero cuando estos son producidos por Glycine max y Medicago sativa, los mismos actúan como inhibidores de la germinación de esporas. ${ }^{318}$ Así, este tipo de señalización es extremadamente sensitiva al simbionte y hospedero, de manera de asegurara que solo asociaciones muy específicas pueden ser implementadas.

Sin embargo, algunas observaciones sugieren que no todas las plantas han desarrollado estrategias adaptativas a partir de las posibles interacciones con la biótica del suelo, con el fin de reducir o inhibir microbios patogénicos y encontrar asociaciones beneficiosas con microbios. Algunos trabajos han reportado que la rizosecreción del isofalvonoide genistein por exudado de raíz por Lupinus luteus L., resulta en un aumento en la atracción hacia hongos patogénicos. ${ }^{315}$ Por otra parte, se ha demostrado que los exudados de la raíz de ciertas plantas pueden promover de manera significativa el crecimiento de hongos patógenos. Tal es el caso de la secreción de ginsenosida, aislado tanto de la rizósfera como de los exudados de la raíz por American ginsens, promueve el crecimiento de dos hongos, Phytophthora cactorum y Phythium irregulare, donde se ha postulado que ese efecto atractor y estimulante del crecimiento, puede afectar la susceptibilidad de esta especie a la presencia de estos hongos patogénicos, representando una fenómeno de pobre adaptación. ${ }^{319} \mathrm{De}$ esta manera, las interacciones planta-microorganismos a través de los exudados de la raíz, o rizointeracción, puede tener una influencia positiva para el crecimiento de las plantas, mediante una gran variedad de mecanismo, como aumento en la fijación de nitrógeno atmosférico por diferentes clases de protobacterias, incremento de la tolerancia al estrés tanto biótico como abiótico mediante la presencia de microbios endofíticos, y ventajas directas o indirectas por la presencia de rizobacterias promotoras del crecimiento vegetativo de las plantas. Las bacterias también pueden causar interacciones positivas con las plantas mediante la formación de antibióticos que frenaran la acción de posibles patógenos, o biodegradar los compuestos inicialmente excretado a la rizósfera por la planta, cuyo producto de esta biotransformación puede ser o poseer potencial alelopático, y en algunos casos, ser auto tóxicos. Este último hecho ha motivado el inicio del estudio del destino final de los potenciales aleloquímicos unas ves depositadas en la rizósfera o en el suelo. Sin embargo, no todo lo que sucede en la biótica de la rizósfera puede ser considerado beneficioso para la integridad sucesional de la población de plantas, pues algunos patógenos y parásitos, afectan de manera negativa su desarrollo. El intercambio de mensajeros químicos entre las plantas y algunos microbios, forma una matriz compleja, cuyo resultado puede ser maligno o benigno para la planta. A pesar de estos antecedentes que muestran la importancia de los microorganismos en el proceso de exudación y los efectos que esto puede causar en el micro hábitat de la planta, poca relevancia se le ha dado a la presencia de diferentes microorganismo al momento de evaluar el potencial alelopático de algunas especies, y menos aun, al momento de aislar e identificar los compuestos químicos o aleloquímicos, que son responsables de los efectos observados.

Por ejemplo, la mayoría de los estudios de los análisis químicos de los exudados de la raíz son llevados a cabo tratando de minimizar precisamente la presencia de microorganismo en el medio, esterilizando tanto el material biológico como materiales del diseño del bioensyo. En el mejor de los casos, algunos estudios de biotransformación con algunos hongos y bacterias específicas in vitro son realizados en la búsqueda de posibles productos biotransformados, como posibles responsables de las actividades medidas. De esta manera, el fenómeno del exudado de la raíz están siendo hoy día enfocados primeramente a entender desde un punto de vista la biológico del proceso de exudación, usando la caracterización química como una técnica de diagnóstico de cambios en los mecanismo de exudado, y a partir de esta información, tratar de entender los proceso que regulan la abundancia y distribución de las plantas, y como paso siguiente, aislar los compuestos verdaderos en los exudaos responsables de la distribución poblacional observados, donde se incluyen los factores de stress sobre la planta, y en especial énfasis, en las interacciones causadas por estos exudados en la biótica o microorganismos de la rizósfera, y a su ves, los cambios en la fisiología de la planta, como respuesta a las señales transmitidas por estos microorganismo.

\section{CONCLUSIONES}

A partir de finales de los años noventa, se ha despertado un gran interés en la caracterización funcional de los exudados de la raíz, tanto desde un punto de vista fisiológico como químico. Básicamente, en el campo de la ecología, los estudios del fenómeno alelopático han sido orientados a los factores que pueden modificar la riqueza química de estos exudados, tanto su concentración como de las diferentes especies químicas que puedan contener. El papel de los exudados de la raíz en fenómenos como simbiosis raíz microorganismo, en la adquisición de nutrientes, y más recientemente, en la capacidad adaptativa de la planta, están siendo considerados como la clave para entender la capacidad de adaptación de la planta bajo determinadas condiciones, y desde el punto de vista del fenómeno alelopático, están siendo estudiados como un mecanismo fundamental en la competencia que están muestran por el espacio y nutrientes. Este tipo de interés no es solo puramente científico, las consecuencias que el entendimiento del fenómeno de exudación y su intervención en la comunicación de la planta con su entorno, pueden repercutir profundamente en aspectos prácticos tales como la agricultura. Cada vez crece la necesidad de mejorar las prácticas de manejo de cultivos dirigidos hacia una agricultura sustentables. Entender el mecanismo de exudación de un compuesto el cual ha demostrado ser activo frente 
a diferentes especies, y las variables que pueden modificar sus niveles de concentración, pueden originar cosechas con una mayor capacidad de competencias frente a otras especies consideradas como malas hiervas. De esta manera, la necesidad de utilizar agentes químicos de control puede disminuirse, originando una disminución en la resistencia a herbicidas. Desde el punto de las diferentes metodologías abordadas para estudiar tanto los exudados, como sus efectos sobre otras especies, existen serias dificultades. Sin embargo, los últimos avances en este sentido se han desarrollado básicamente en los sistemas de crecimiento, el análisis y la metodología de captura y pre concentración de los exudados. Diferentes factores que afectan los niveles de exudados han sido incluidos recientemente, tales como la septicidad del sistema de crecimiento y la resistencia mecánica al crecimiento, han demostrado ser de considerable importancia en la variabilidad de la emisión de compuestos en los exudados de la raíz. Desde un punto de vista biológico, actualmente se está abordando el estudio del efecto de la poliploidia inducida y el efecto que este tiene, tanto en la concentración endógena como exógena de sus potenciales transmisores de información.

Para el estudio del fenómeno alelopático, y su total comprobación de su operatividad a nivel de campo, el panorama resulta muy difícil, pues además de las diferentes variables biológicas e instrumentales o prácticas señaladas, se suma el efecto que la rizósfera puede tener sobre todas las moléculas traslocadas al ambiente, pues esta rizosfera puede modificar la velocidad del proceso de exudación, los niveles de concentración, movilidad y disponibilidad de los nutrientes debido a su interacción con las moléculas exudadas. Todos estos factores pueden ser sinérgicos, aditivos o inhibidores de un modo de acción en particular de la interacción planta-planta. Debido a esta complejidad, el estudio de la alelopatía cada vez requiere de una mayor confluencia de diferentes especialidades confiriéndole un carácter multidisciplinario. La integración de diferentes ramas de la ciencia; tales como ciencia de los suelos, microbiología de suelo, fisiología de las plantas, técnicas de análisis químicos y biología molecular, serán sin duda forzadas a unirse para poder entender y demostrar la presencia de competencia entre plantas, y más específicamente la implementación del fenómeno alelopático. De todo esto, la demostración del fenómeno alelopático representa un gran desafió para los químicos ecólogo, la cual tiene lugar mediante un fiel seguimiento del o los aleloquímicos responsable de los efectos observados. Esto implica estudiar la dinámica del compuesto en la planta donadora, su traslocación o síntesis de este en el sistema radicular, y como proceso determinante del fenómeno, la liberación al entorno este compuesto. Una vez en el suelo, el aleloquímico interactúa física, química o biológicamente con los componentes de la rizósfera, y lo que resulte de esta interacción son las especies que interaccionaran con el ente receptor, y es allí donde ocurre el último paso de la ruta alelopática, que es determinar la presencia del aleloquímico o sus derivados en la especie receptora, lo cual nunca es llevado a cabo en los estudios sobre el tema. Así, todos estos niveles de estudios, denominado el ciclo alelopático, no han sido cubiertos de una manera simultánea ni dinámica en los diferentes estudios del fenómeno; con lo cual el mayor reto que se presenta hoy día en el campo de la alelopatía es demostrar dicho fenómeno, al menos a nivel de laboratorio.

\section{AGRADECIMIENTOS}

Este trabajo fue financiado por el programa 'Quality of life and management of living resources (1998 to 2002)' de la Union Europea, FATEALLCHEM contract no. QLK5-CT-2001-01967. Becas de la Universidad de los Andes-Venezuela (A. O. B.) y de la comisión Europea (Unión Europea) y Junta de Andalucía-España (D. M.) son también agradecidas.

\section{REFERENCIAS}

1. Gniazdowska, A.; Bogatek, R.; Acta Physiol. Plantarum 2005, 27, 395.

2. Bais, H.; Vepachedu, R.; Gilroy, S.; Callaway, R.; Vivanco, J.; Science 2003, 301, 1377.

3. Inderjit, D. S.; Planta 2003, 217, 529.

4. Walling, L.; J. Plant Growth Regul. 2000, 19, 195.

5. Dudareva, N.; Negre, F.; Curr. Opin. Plant Biol. 2005, 8, 113.

6. Kessler, A.; Baldwin, I.; Science 2001, 291, 2141.

7. Watanabe, S.; Aroma Res. 2005, 6, 214.

8. Paré, P.; Tumlinson, J.; Plant Physiol. 1999, 121, 325.

9. Baumeler, A.; Hesse, M.; Werne, Ch.; Phytochemistry 2000, 53, 213.

10. Zuniga, G.; Massardo, F.; Phytochemistry 1991, 30, 3281.

11. Ma, Y.; Weed Biol. Manage. 2005, 5, 93.

12. Nguyen, Ch.; Agronomie 2003, 23, 375.

13. Maplestone, R.; Stone, M.; Williams, D.; Genet. 1992, 115, 151.

14. Theis, N.; Lerdau, M.; Int. J. Plant Sci. 2003, 164, S93.

15. Stone, M.; Williams, D.; Mol. Microbiol. 1992, 6, 29.

16. Jarvis, B.; Recent Adv. Phytochem. Elsevier Science Ltd., 2000, p. $1-24$.

17. Rengel, Z.; Plant Soil 2002, 245, 59.

18. Hartmann, T.; Entomol. Exp. Appl. 1996, 80, 177.

19. McLean, S.; Pass, G.; Foley, W.; Brandon, S.; Davies, N.; J. Chem. Ecol. 2001, 27, 1077.

20. Muller, C.; Bull. Torrey Bot. Club 1966, 93, 332.

21. Chou, Ch.; Crit. Rev. Plant Sci. 1999, 18, 609.

22. Molish, H.; Die Einfluss siner Pflanze auf die andere-Allelopathie, Gustav Fischer: Jena, 1937.

23. Rice, E.; Allelopathy, $2^{\text {nd }}$ ed., Academic Press: Orlando, 1984.

24. http://www-ias.uca.es/bylaws.htm\#CONSTI, accesada en Febrero 2008.

25. Hierro, J.; Callaway, R.; Plant Soil 2003, 256, 29.

26. Weir, T.; Park, S.; Vivanco, J.; Curr. Opin. Plant Biol. 2004, 7, 472.

27. Inderjit; Dakschini, K.; Bot. Rev. 1994, 60,182.

28. Putnam, A.; Duke, S.; Annu. Rev. Phytopathol. 1978, 16, 431; Wardle, D.; Nilsson, M.; Gallet, C.; Zackrisson, O.; Biolo. Rev. 1998, 73, 305.

29. Wardle, D. A.; Nilsson, M.; Gallet, C.; Zackrisson, O.; Biol. Rev. 1998, 73,305 .

30. Inderjit; Callaway, R.; Plant Soil 2003, 256, 1.

31. Suikkanen, S.; Fistarol, G.; Graneli, E.; J. Exp. Mari. Biol. Ecol. 2004, 308,85 .

32. Fitter, A.; Science 2003, 301, 1337

33. Vivanco, J.; Baiz, H.; Stermitz, T.; Thelen, G.; Callaway, R.; Ecol. Lett. 2004, 7,285

34. Inderjit; Weiner, J.; Perspectives Plant Ecol. Evol. Syst. 2001, 4, 3.

35. Inderjit; Nilsen, E.; Crit. Rev. Plant Sci. 2003, 22, 221.

36. Inderjit; Keating, K.; Adv. Agron. 1999, 67, 141.

37. Massey, A.; Phytopathol. 1925, 15, 774.

38. Davis, E.; Am. J.Bot. 1928, 15, 620.

39. Wardle, D.; Nilsson, M.; Gallet, C.; Zackrisson, O.; Biol. Rev. 1998, 73, 305 .

40. Hartung, A.; Stephens, C.; J. Chem. Ecol. 1983, 8, 1163.

41. Inoue, M.; Nishimura, H.; Li, H.; Mizutani, J.; J. Chem. Ecol. 1992, 18, 1833.

42. Perry, D. A.; Choquette, C. En Allelopathic effects on mycorrhizae: influence on structure and dynamics of forest ecosystems; Waller, G. R., ed.; American Chemical Society: Washington, 1987, p. 358-370.

43. Allison, M.F.; Killham, K.; J. Soil Sci. 1988, 39, 237.

44. Mizutani, J.; Crit. Rev. Plant Sci. 1999, 18, 653.

45. Sing, H.; Batisch, D.; Kohli, R.; Crit. Rev. Plant Sci. 2003, 22, 239.

46. Reberg-Horton, S.; Burton, J.; Danehower, D.; Ma, G.; Monks, D.; 
Murphy, J.; Ranells, N.; Williamson, J.; Creamer, N.; J. Chem. Ecol. 2005, 31, 179.

47. Yongqing, M.; Weed Biol. Manage. 2005, 5, 93.

48. Higashinakasu, K.; Yamada, K.; Shigemori, H.; Hasegawa, K.; Heterocycl. 2005, 65, 1431.

49. Nishihara, E.; Parvez, M.; Araya, H.; Kawashima, S.; Fujii, Y.; J. Plant Growth Regul. 2005, 45, 113.

50. Seal, A.; Haig, T.; Pratley, J.; J.Chem. Ecol. 2004, 30, 1663.

51. Kato-Noguchi, H.; J. Plant Physiol. 2004, 161, 271.

52. Wu, H.; Haig, T.; Pratley, J.; Lemerle, D.; An, M.; J. Chem. Ecol. 2000, 26, 2141.

53. Belz, R.; Hurle, K.; J. Agric. Food Chem. 2005, 53, 250.

54. Perez, F.; Ormeno-Nunez, J.; J. Chem. Ecol. 1991, 17, 1037.

55. Kaur, H.; Inderjit; K.; Plant Physiol. Biochem. 2005, 43, 77.

56. Bravo, H.; Copaja, S.; Argandona, V.; J. Agric. Food Chem. 2004, 52, 2598.

57. Burgos, N.; Talbert, R.; Kim, K.; Kuk, Y.; J. Chem. Ecol. 2004, 30, 671.

58. Blum, U.; Allelopathy 2004, 57.

59. Cheng, H.; Koskinen, W.; Dev. Soil Sci.2002, ??, 134.

60. Blum, U.; Shafer, S.; Lehman, M.; Crit. Rev. Plant Sci. 1999, 18, 673.

61. Ito, I.; Kobayashi, K.; Yoneyama, T.; Ann. Bot. 1998, 82, 625.

62. Inderjit; Plant Soil 2005, 274, 227.

63. Schmidt, S.; Lipson, D.; Plant Soil 2004, 259, 1.

64. Inderjit; Agronomy J. 2001, 93, 79.

65. An, M.; Pratley, J.; Haig, T.; J. Chem. Ecol. 2000, 26, 2603.

66. Lehman, M.; Blum, U.; J. Chem. Ecol. 1999, 25, 2585.

67. Gardiner, J.; Morra, M.; Eberlein, Ch.; Brown, P.; Borek, V.; J. Agri. Food Chem. 1999, 47, 3837.

68. Schmidt, S.; Ley, R. En Microbial competition and soil structure limit the expression of allelochemicals in nature; Inderjit, ??; Dakshini, K. M. M.; Foy, Chester, L., eds.; CRC: Boca Raton, 1999, p. 339-351.

69. Chiapusio, G.; Pellissier, F.; J. Chem. Ecol. 2001, 27, 1701.

70. Shann, J.; Blum, U.; Phytochemistry 1987, 26, 2959.

71. Hachinohe, M.; Sunohara, Y.; Matsumoto, H.; J. Plant Growth Regul. 2004, 43, 237

72. Hiradate, S.; Furubayashi, A.; Fujii, Y.; Soil Sci. Plant Nutr. 2005, 51, 477.

73. Burgos, N.; Talbert R.; Kim, K.; Kuk, Y.; J. Chem. Ecol. 2004, 30, 671.

74. Weiland, I.; Friebe, A.; Kluge, M.; Sicker, D.; Schulz, M. En Detoxification of benzoxazolinone in higher plant; Macias, F. A.; Galindo, J. C.; Molinillo, J.; Cutler, H., eds.; Madrid: S.A.I. Universidad de Cadiz, 1999, vol. 1, p. 47-56.

75. Weiland, I.; Kluge, M.; Schneides, B.; Schmidt, B.; Sicker, D.; Schulz, M.; Phytochemistry 1998, 49, 719.

76. Sicker, D.; Schneider, B.; Henning, L.; Knop, M.; Schulz, M.; Phytochemistry 2001, 58, 819.

77. Von rad, U.; Huttl, R.; Lottspiech, F.; Gierl, A.; Frey, M.; J. Plant. 2001, $28,633$.

78. Baerson, S.; Sanchez-Moreiras, A.; Pedrol-Bonjoch, N.; Schulz, M.; Kagan, I.; Agarwal, A.; Reigosa, M.; Duke, S.; J. Biol. Chem. 2005, 280, 21867.

79. Sicker, D.; Hao, H.; Schulz, M.; Allelopathy 2004, 77.

80. Schulz, M.; Friebe, A. En Detoxification of allelochemicals in higher plants and enzymes involved; Dakshini, K. M; Foy, Ch., eds.; Springer: Netherlands, 1999, cap. 8.

81. Schulz, M.; Schnabl, H.; Manthe, B.; Schweihofen, B.; Casser, I.; Phytochemistry 1993, 33, 291.

82. Bertin, C.; Yang, X.; Weston, L.; Plant Soil 2003, 256, 67.

83. Estabrook, E.; Yoder, J.; Plant Physiol. 1998, 116, 1.

84. Kobayashi, K.; Weed Biol. Management. 2004, 4, 1.

85. Paynel, F.; Murray, P.; Cliquet, J.; Plant Soil 2001, 229, 235.
86. Groleau-Renaud, V.; Plantureux, S.; Tubeileh, A.; Guckert, A.; J. Plant Nutr. 2000, 23, 1283.

87. Birkett, M.; Chamberlain, K.; Hooper, A.; Pickett, J.; Plant and Soil 2001, 232, 31.

88. Weir, T.; Park, S.; Vivanco, J.; Curr. Opin. Plant Biol. 2004, 7, 472.

89. McCully, M.; Annu. Rev. Plant Physiol. Plant Mol. Biol. 1999, 50, 695.

90. Schmidt, S.; J. Chem. Ecol. 1988, 14, 1561.

91. Walker, T.; Bais, H.; Grotewold, E.; Vivanco, J.; Plant Physiol. 2003, 132, 44.

92. Blum, U.; Gering, T.; Worsham, A.; King, L.; J. Chem. Ecol. 1993, 19, 2791.

93. Pue, K.; Gerig, T.; Shafer, S.; J. Chem. Ecol. 1995, 21, 833.

94. Inderjit; Dakshini, K. En Bioassays for allelopathy: interactions of soil organic and inorganic constituents; Inderjit; Dakshini, K. M. M.; Foy, C. L., eds.; CRC: Boca Raton, 1999, p. 35.

95. Inderjit; Weiner, J.; Perspectives Plant Ecol. Evol. Syst. 2001, 4, 3.

96. Brown, W.; Eisner, T.; Whittaker, R.; Biosci. 1970, 20, 21.

97. Nordlund, D.; Lewis, W.; J. Chem. Ecol. 1976, 2, 211.

98. Metcalf, R.; Metcalf, E.; Plant kairomones in insect ecology and control, Kluwer Academic Publishers: London, 1992, cap. 1.

99. Yazaki, K.; Curr. Opin. Plant Biol. 2005, 8, 301.

100. Martinoia, E.; Massonneau, A.; Frangne, N.; Plant Cell Physiol. 2000, 41,1175

101. Nishida, N.; Tamotsu, S.; Nagata, N.; Saito, Ch.; Sakai, A.; J. Chem. Ecol. 2005, 31, 1187

102. Aharoni, A.; Jongsma, M.; Bouwmeester, H.; Trends Plant Sci. 2005, 10, 594.

103. Kong, C.; Hu, F.; Xu, X.; J. Chem. Ecol. 2002, 28, 1173.

104. Kong, C.; Hu, F.; Xu, X.; Zhang, M.; Liang, W.; J. Chem. Ecol. 2005, 31,2193

105. Kessler, A.; Baldwin, I.; Science 2001, 291, 2141.

106. Barney, J. N.; Hay, A. G.; Weston, L. A.; J. Chem. Ecol. 2005, 31, 247.

107. Nishida, N.; Tamotsu, S.; Nagata, N.; Saito, Ch.; Sakai, A.; J. Chem. Ecol. 2005, 31, 1187

108. Anaya, A.; Calera, M.; Mata, R.; Pereda-Miranda, R.; J. Chem. Ecol. 1990, 16, 2145.

109. Chou, Ch.; J. Chem. Ecol. 1989, 15, 2149.

110. Cruz-Ortega, R.; Ayala-Cordero, G.; Anaya, A.; Physiol. Plant 2002, 116, 20.

111. Molina, A.; Reigosa, M. J.; Carballeira, A.; J. Chem. Ecol. 1991, 17, 147.

112. Buta, J.; Spaulding, D.; J. Chem. Ecol. 1989, 15, 1629.

113. Barazani O; Friedman, J.; Crit. Rev. Microbiol. 2001, 27, 41.

114. Weston, L.; Duke, S.; Crit. Rev. Plant Sci. 2003, 22, 367.

115. An, M.; Pratley, J.; Haig, T.; J. Chem. Ecol. 2001, 27, 395.

116. Koch, H.; Matthiessen, A.; Baeumer, K.; J. Agronomy Crop Sci. 1992, 169, 184

117. An, M.; Pratley, J.; Haig, T.; J. Chem. Ecol. 2000, 26, 2603.

118. Masiunas, J.; Weston, L.; Weller, S.; Weed Sci.. 1995, 43, 318.

119. Seal, A.; Haig, T.; Pratley, J.; J. Chem. Ecol. 2004, 30, 1663.

120. Seal, A.; Pratley, J.; Haig, T.; An, Min.; J. Chem. Ecol. 2004, 30, 1647.

121. Kato-Noguchi, H.; J. Plant Physiol. 2004, 161, 271.

122. Kong, Ch., Liang, W.; Xu, X.; Hu, F.; Wang, P.; Jiang, Y.; J. Agric. Food Chem. 2004, 52, 2861.

123. Huang, Z.; Haig, T.; Wu, H.; An, M.; Pratley, J.; J. Chem. Ecol. 2003, $29,2263$.

124. Czarnota, M.; Rimando, A.; Weston, L., J. Chem. Ecol. 2003, 29, 2073.

125. Yu, J.; Ye, S.; Feng; Z.; Ming F.; Hu, W.; Biochem. Syst. Ecol. 2003, 31, 129.

126. Kato-Noguchi, H.; Ino, T.; Sata, N.; Yamamura, S.; Physiol. Plant. 2002, 115,401 
127. Kato-Noguchi, H.; Mizutani, J.; Hasegawa, K.; J. Chem. Ecol. 1994, 20 315 .

128. Aharoni, A.; Jongsma, M.; Bouwmeester, H.; Trends Plant Sci. 2005, 10, 594.

129. Inderjit; Weston, L. En Root exudates: an overview; de Kroon, H.; Visser, E., eds.; Springer: Berlin Heidelberg New York, 2003, p 235255.

130. Weidenhamer, J.; J. Agron. 1996, 88, 866.

131. Fuerst, E.; Putnam, A.; J. Chem. Ecol. 1983, 9, 937.

132. Feldman, L.; Annu. Rev. Plant Physiol. 1984, 35, 223.

133. Sturz, A.; Christie, B.; Soil Tillage Res. 2003, 72, 107.

134. Bernston, G.; New Phytol. 1994, 127, 483.

135. Spek, L.; Plant Soil 1997, 197, 9.

136. Thaler, P.; Page, L.; Plant Soil 1998, 201, 307.

137. Lopez-Bucio, J.; Cruz-Ramirez, A.; Perez-Torres, A.; Ramirez-Pimentel, J.; Sanchez-Calderon, L.; Herrera-Estrella, L.; Ann. Plant Rev. 2005, 17, 1460 .

138. Uren, N. En Types, amounts, and possible functions of compounds release into the rhizosphere by soil-grown plant; Pinto, R.; Varanni, Z.; Nannipieri, P., eds.; Marcel Dekker, Inc.: New York, 2000, p. 19-40.

139. Caldwell, M. En Exploiting nutrients in fertile soil microsites; Caldwell, M.; Pearcy, R., eds.; Academic Press: San Diego, 1994, p 325.

140. Gilroy, S.; Jones, D.; Trends Plant Sci. 2000, 5, 56

141. Nye, P.; J. Soil Sci. 1984, 35, 439.

142. Junk, A. En Dynamics of nutrient movement at the soil-root-interface Wasiel, Y.; Eshel, A.; Kafkafi, ??, eds.; Marcel Dekker, Inc.: New York, 2002, p. 587

143. Hinsinger, P.; Adv. Agronomy 1998, 64, 225

144. Whipps, J.; Lynch, J.; New Phytol. 1983, 95, 605.

145. Crews, L.; McCully, M.; Canny, M.; Funct. Plant Biol. 2003, 30, 755.

146. Read, D.; Gregory, P.; Bell, A.; Plant Soil 1999, 211, 87.

147. Marschner, H.; Mineral Nutrition of Higher Plants, $2^{\text {nd }}$ ed., Academic Press, Inc.: San Diego, 1995.

148. Gonzalez-Lopez, J.; Martinez-Toledo, M. V.; Reina, S.; Salmeron, V.; Toxicol. Environ. Chem. 1991, 33, 69.

149. Rovira, A.; Harris, J.; Plant Soil 1961, 14, 199.

150. Rovira, A. D.; Foster, R. C.; Martín, J. En Note on terminology: origin, nature and nomenclature of the organic materials in the rhizosphere; Harley, J. L.; Russell, R., eds.; Academic Press: London, 1999, p. 1.

151. Bais, H.; Park, S.; Weir, T.; Callaway, R.; Vivanco, J.; Trends Plant Sci. 2004, 9, 26.

152. Gransee, A.; Wittenmayer, L.; J. Plant Nutri. Soil Sci. 2000, 163,381.

153. Stroem, L.; Olsson, T.; Tyler, G.; Plant Soil 1994, 167, 239.

154. Collmer, A.; Keen, N.; Annu. Rev. Phytopathol. 1986, 24, 383.

155. Prikryl, L.; Vancura, V.; Plant Soil 1980, 57, 69.

156. Juszczuk, I.; Wiktorowska, A.; Malusa, E.; Rychter, A.; Plant Soil 2004, $267,41$.

157. Hoffland, E.; Findenegg, G.; Nelemans, J.; Plant Soil 1989, 113, 161.

158. Wittenmayer, L.; Merbach, W.; J. Plant Nutr. Soil Sci. 2005, 168, 531.

159. Barber, D., Martin, J.; New Phytol. 1976, 76, 69.

160. Gibbs, J.; Turner, D. W.; Armstrong, W.; Sivasithamparam, K.; Greenway, H.; Australian J. Plant Physiol. 1998, 25,7 59.

161. Grineva, G.; Soviet Plant Physiol. 1961, 8, 5498.

162. Groleau-Renaud, V.; Plantureaux, S.; Guckert, A.; Plant Soil 1998, 201, 231.

163. Boeuf-Tremblay, V.; Plantureux, S.; Guckert, A.; Plant Soil 1995, 172, 279.

164. Pomilio, A.; Leicach, S.; Grass, M.; Ghersa, C.; Santoro, M.; Vitale, A.; Phytochem. Anal. 2000, 11, 304.

165. Paterson, E.; Thornton, B.; Sim, A.; Pratt, S.; Plant Soil 2003, 250 , 293.

166. Bais, H.; Loyola-Vargas, V.; Flores, H.; Vivanco, J.; In Vitro Plant 2001, 37, 730 .
167. Pramanik, M.; Nagal, M.; Asao, M., Matsui, Y.; J. Chem. Ecol. 2000, 26, 1953.

168. Fan, T.; Lane, A.; Crowley, D.; Higashi, R.; Anal. Biochem. 1997, 251,57.

169. Ponce, M.; Scervino, J.; Erra-Balsells, R.; Ocampo, J.; Godeas, A.; Phytochemistry 2004, 65, 3131.

170. Thompson, L.; Hale, M.; Soil Biol. Biosci. 1983, 15, 125.

171. Weidenhamer, J.; J. Chem. Ecol. 2005, 31, 221.

172. Campbell, G.; Lambert, J.; Arnason, T., Towers, G.; J. Chem. Ecol. 1982, $8,961$.

173. Duke, S.; Vaughn, K.; Croom, E.; Elsohly, H.; Weed Sci. 1987, 35, 499.

174. Einhellig, F.; Souza, I.; J. Chem. Ecol. 1992, 18, 1.

175. Nimbal, Ch.; Pedersen, J.; Yerkes, C.; Weston, L.; Weller, S.; J. Agric. Food Chem. 1996, 44, 1343.

176. Kato, T.; Kabuto, Ch.; Sasaki, N.; Tsunagawa, M.; Aizawa, H.; Fujita, K.; Kato, Y.; Kitahara, Y.; Takahashi, N.; Tetrahedron Lett. 1973, 39, 3861.

177. Takahashi, N.; Kato, T.; Tsunagawa, M.; Sasaki, N.; Kitahara, Y.; Jpn. J. Breed. 1976, 26, 91.

178. Perez, F.; Ormeño-Nuñez, J.; J. Chem. Ecol. 1991, 17, 1037.

179. Wu, H.; Haig, T.; Pratley, J.; Lemerle, D.; An, M.; J. Chem. Ecol. 2001, 27,1691 .

180. Higashinakasu, K.; Yamada, K.; Shigemori, H.; Hasegawa, K.; Heterocycles 2005, 65, 267.

181. Yamane, A.; Fujikura, J.; Ogawa, H.; Mizutani, J.; J. Chem. Ecol. 1992, $18,1941$.

182. Hunter, R.; Halloin, J.; Veech, J.; Carter, W.; Plant Soil 1978, 50, 237.

183. Steeghs, M.; Bais, H.; de Gouw, J.; Goldan, P.; Kuster, W.; Northway, M.; Fall, R.; Vivanco, J.; Plant Physiol. 2004, 135, 47.

184. Pomilio, A.; Leicach, S.; Grass, M.; Ghersa, C.; Santoro, M.; Vitale, A.; Phytochem. Anal. 2000, 11, 304.

185. Akiyama, K.; Matsuzaki, K.; Hayashi, H.; Nature 2005, 435, 824

186.Matusova, R.; Rani, K.; Verstappen, F.; Franssen, M.; Beale, M.; Bouwmeester, H.; Plant Physiol. 2005, 139, 920.

187. Nicol, R.; Yousef, L.; Traquair, J.; Bernards, M.; Phytochemistry 2003, 64, 257.

188. Perez, F.; Ormeño-Nunez, J.; Phytochemistry 1991, 30, 2199.

189. Yasuda, K.; Kojima, M.; Agr. Biol. Chem. 1986, 50, 1839.

190. Grensee, A., Wittmayer, L.; J. Plant Nut. Soil Sci. 2000, 163, 381.

191. Palta, J.; Gregory, P.; Soil Biol. Biochem. 1997, 29, 1395.

192. Gianoli, E.; Rios, J.; Niemeyer, H.; Acta Agric. Scand., Sect. B: Soil Plant Sci. 2000, 50, 35

193. Copaja, S.; Nicol, D.; Wratten, S.; Phytochemistry 1999, 50, 17.

194. Argandona, V.; Corcuera, L.; Phytochemistry. 1985, 24, 177.

195. Smith, W.; Ecology. 1976, 57, 324.

196. Seal, A.; Pratley, J.; Haig, T.; An, M.; J. Chem. Ecol. 2004, 30, 1647.

197. Kato-Noguchi, H.; Ino, T.; J. Plant Physiol. 2005, 162, 965.

198. Aulakh, M.; Wassmann, R.; Bueno, C.; Kreuzwieser, J.; Rennenberg, H.; Plant Biol. 2001, 3, 139.

199. Ceballos, L.; Hossaert-McKey, M.; McKey, D.; Andary, C.; Chemoecology 1998, 8,141.

200. Groleau-Renaud, V.; Plantureux, S.; Guckert, A.; Plant Soil 1998, 201, 231.

201. Boeuf-Tremblay, V.; Plantureux, S.; Guckert, A.; Plant Soil 1995, 172 , 279.

202. Barber, D., Gunn, K.; New Phytology. 1974, 73, 39.

203. Dong, D.; Peng, X.; Yan, X.; Physiol. Plant 2004, 122, 190.

204. Weilkie, G.; Miller, G.; Plant Physiol. 1960, 35, 516.

205. Jolley, V., Brown, J.; J. Plant Nutr. 1987, 10, 637.

206. Dakora, F.; Phillips, D.; Plant Soil 2002, 245, 35.

207. Meharg, A.; Killham, K.; Plant Soil 1990, 123, 1.

208. Marschner, H.; Romheld, V.; Cakman, I.; J. Plant Nutr. 1987, 10, 1175 . 
209. Nian, H.; Yang, Z.; Huang, H.; Yan, X.; Matsumoto, H.; J. Plant Nutr. 2004, 27, 1281

210. Svenningsson, H.; Sundin, P.; Liljenberg, C.; Plant, Cell Environ. 1990, 13,155 .

211. Hale, M.; Moore, L.; Griffin, G. En Root exudates and exudation; Dommergues, Y.; Krupa, S., eds.; Elsevier: Amsterdam, 1978, p. 163.

212. Raghuwanshi, A.; Dudeja, S.; Khurana, A.; Biol. Fertility Soils 1994, 17, 314.

213. Buerkert, A.; Marschner, H.; Plant Soil 1992, 147, 293.

214. Smucker, A.; Erickson, A.; Plant Soil 1987, 99, 423

215. Whipps, J., Lynch, J.; Adv. Microbiol. Ecol. 1986, 6, 187.

216. Drew, M.; Annu Rev Plant Physiol. Plant Mol. Biol. 1997, 48, 223.

217. Kato-Noguchi, H.; Phytochemistry 1999, 52, 1023.

218. Paterson, E.; Thornton, B.; Sim, A.; Pratt, S.; Plant Soil 2003, 250, 293.

219. Norby, R., Luxmoore, J., O’Neill, E., Weller, D.; Plant responses to elevated $\mathrm{CO} 2$ atmospheric $\mathrm{CO}_{2}$ with emphasis on belowground processes, Oak Ridge National Laboratory: Oak Ridge, 1984, p.141.

220. Bowes, G.; Annu. Rev. Plant. Physiol. 1993, 309, 332.

221. Lee, K.; Gaskins, M.; Plant Soil 1982, 69, 391.

222. Prikryl, Z.; Vancura, V.; Plant Soil 1980, 57, 69.

223. Kraffczyk, I.; Trolldenier, G.; Beringer, H.; Soil Biol. Biochem. 1984, 16,315 .

224. Guy, C.; J. Mol. Micro. Biotechnol. 1999, 12, 231.

225. Kaplan, F.; Kopka, J.; Haskell, D.; Zhao, W.; Schiller, C.; Gatzke, N.; Sung, D.; Guy, C.; Plant Physiol. 2004, 136, 4159.

226. Gianoli, E.; Niemeyer, H.; J. Chem. Ecol. 1997, 23, 543.

227. Makarova, L.; Rudikovskaya, E.; Agrokhimiya 2003, 8, 61 .

228. Collantes, H.; Gianoli, E.; Niemeyer, H.; J. Chem. Ecol. 1999, 25, 491.

229. Collantes, H.; Gianoli, E.; Niemeyer, H.; Phytochemistry 1998, 49, 1921.

230. Collantes, H.; Gianoli, E.; Niemeyer, H.; Environ. Exp. Bot. 1997, 38, 231.

231. Mwaja, V.; Masiunas, J.; Weston, L.; J. Chem. Ecol. 1995, $21,81$.

232. Niemeyer, H.; Pesel, E.; Copaja, S.; Bravo, H.; Franke, S.; Francke, W.; Phytochemistry 1989, 28, 447.

233. Thomas, F.; Schafellner, Ch.; J. Appl. Bot. 1999, 73, 222.

234. Kochian, V.; Pence, N.; Letham, D.; Pineros, M.; Magalhaes, J.; Hoekenga, O.; Garvin, D.; Plant Soil 2002, 247, 109.

235. Kollmeier, M.; Dietrich, P.; Bauer, C.; Horst, W.; Hedrich, R.; Plant Physiol. 2001, 126, 397.

236. Carter, N., McLean, I., Watt, A., Dixon, A.; Appl. Biol. 1980, 5, 271.

237. Quiroz, A.; Pettersson, J.; Pickett, J.; Wadhams, L.; Niemeyer, H.; J. Chem. Ecol. 1997, 23, 2599.

238. Chamberlain, K.; Guerrieri, E.; Pennacchio, F.; Pettersson, J.; Pickett, J.; Poppy, G.; Powell, W.; Wadhams, L.; Woodcock, C.; Biochem. Syst. Ecol. 2001, 29, 1063.

239. Corcuera, L. J.; Argandona, V. H.; Niemeyer, H. M. En Effect of cyclic hydroxamic acids from cereals on aphids Chem. Biol. Hydroxamic Acids; Kehl, H., ed.; Karger, A.G.: Basel, 1982, cap. 13.

240. Leszczynski, B.; Matok, H.; Dixon, A.; J. Chem. Ecol. 1992, 18, 1189.

241. Gianoli, E.; Niemeyer, H.; Chemoecology 1998, 8, 19.

242. McCully, M., Canny, M.; Physiol. Plant. 1985, 65, 380.

243. Jones, D., Darrah, P.; Plant Soil 1996, 178, 153.

244. Saxena, D.; Stotzky, G.; Soil Biol. Biochem. 2001, 33, 1225.

245. Saxena, D.; Stewart, C.; Altosaar, I.; Shu, O.; Stotzky, G.; Plant Physiol. Biochem. 2004, 42, 383.

246. Dayan, F.; Romagni, J.; Duke, S.; J. Chem. Ecol. 2000, 26, 2079.

247. Duke, S.; Rimando, A.; Dayan, F.; Canel, C.; Wedge, D.; Tellez, M.; Schrader, K.; Weston, L.; Smillie, T.; Paul, R.; Duke, M. En Strategies for the discovery of bioactive phytochemicals; Bidlack, W.; Omaye, S.; Meskin, M.; Topham, D., eds.; Technomic Publishing Co., Inc.: Lancaster, 2000, cap. 1.
248. Duke, S.; Dayan, F.; Romagni, J.; Rimando, A.; Weed Res. 2000, 40, 99.

249. Bais, H.; Loyola-Vargas, V; Flores, H.; Vivanco, J.; Plant. 2001, 37, 730.

250. Tanaka, N.; Matsumoto, T.; Plant Cell Rep. 1993, 13, 87.

251. Babakov, A.; Bartova, L.; Dridze, I.; Maisuryan, A.; Margulis, G.; Oganian, R.; Voblikova, V.; Muromtsev, G.; J. Plant Growth Regul. 1995, 14, 163.

252. Qin Ming-bo, L.; Guo-zhen, Y.; He-chun,Y.; Guo-feng,L.; Acta Bot. Sinica 1994, 36, 165.

253. Trypsteen, M.; Lijsebettens, M.; Severen, R.; Montagu, M.; Plant Cell Rep. 1991, 10, 85 .

254. Brigham, L., Michaels, P.; Flores, H.; Plant Physiol. 1999, 119, 417.

255. Yamanaka, M.; Ishibashi, K.; Shimomura, K.; Ishimaru, K.; Phytochemistry 1996, 41, 183.

256. Benjamin, B., Roja, G.; Heble, M.; Phytochemistry 1994, 35, 381.

257. Sato, K.; Yamazaki, T.; Okuyama, E.; Yoshihira, K.; Shimomura, K.; Phytochemistry 1991, 30, 1507.

258. Hu, Z.; Alfermann, A.; Phytochemistry 1993, 32, 699

259. Delbecque, J.; Beydon, P.; Chapuis, L.; Corio-Costet, M.; Eur. J. Entomol .1995, 92, 301.

260. Takeda, T.; Kondo, T.; Mizukami, H.; Ogihara, Y.; Chem. Pharmacol. Bull. 1994, 42, 730

261. Graenicher, F.; Christen, P.; Kamalaprija, P.; Burger, U.; Phytochemistry 1995, 38, 103.

262. Huoa, Ch.; Wanga, B.; Linb, W.; Zhao, Y.; Biochem. System. Ecol. 2005, $33,643$.

263. Bravo, H.; Copaja, S.; San Martin, J.; Zeitschrift fuer Naturforschung, C: J. Biosci. 2004, 59, 177.

264. Pratt, K.; Kumar, P.; Chilton, W.; Biochem. System. Ecol. 1995, 23, 781.

265. Stermitz, F.; Bais, H.; Foderaro, T.; Vivanco, J.; Phytochemistry 2003, 64,493 .

266. Friebe, A.; Schulz, M.; Kock, P.; Schnab, H.; Phytochemistry 1995, 38, 1157.

267. Wenhao, Y.; Shuwen, Y.; Shanyuan, Z.; Pinwen, Y.; Ziwen, W.; Houming, H.; Shengyu, T.; Zhiwu Shengli Xuebao 1993, 19, 92.

268. Nishimura, H.; Li, H.; Mizutani, J.; J. Chem. Ecol. 1992, 18, 1833.

269. Pérez, F.; Ormeño-Nuñeza, J.; Phytochemistry 1991, 30, 2199.

270. Schumacher, W.; Thill, D.; Lee, G.; J. Chem. Ecol. 1983, 9, 1235

271. Yokose, T.; Katamoto, K.; Park, S.; Matsuura, H.; Yoshihara, T.; Biosci. Biotechnol. Biochem. 2004, 68, 2640.

272. Sandnes, A.; Eldhuset, T.; Wollebaek, G.; Soil Biol.Biochem. 2005, 37 , 259.

273. Ponce, M.; Scervino, J.; Erra-Balsells, R.; Ocampo, J.; Godeas, A.; Phytochemistry 2004, 65, 3131.

274. Park, S.; Takano, Y.; Matsuura, H.; Yoshihara, T.; Biosci. Biotechnol. Biochem. 2004, 68, 1366.

275. Tsanuo, M.; Hassanali, A.; Hooper, A.; Khan, Z.; Kaberia, F.; Pickett, J.; Wadhams, L.; Phytochemistry 2003, 64, 265.

276. Pal Bais, H.; Park, S.; Stermitz, F.; Halligan, K.; Vivanco, J.; Phytochemistry 2002, 61, 539.

277. Thelen, G.; Vivanco, J.; Newingham, B.; Good, W.; Bais, H.; Landres, P.; Caesar, A.; Callaway, R.; Ecol. Lett. 2005, 8, 209.

278. Mandal, S.; Weed Biol. Manage. 2001, 1, 170

279. Stavrianakaou, S.; Liakopoulos, G.; Karabourniotis, G.; Environ. Exp. Bot. 2006, 53, 293

280. Shen, H.; Yan, X.; Zhao, M.; Zheng, S.; Wang, X.; Environ. Exp. Bot. 2002, 48,1 .

281. Kloss, M.; Iwannek, K.; Fendrik, I.; Niemann, G.; Environ. Exp. Bot. 1984, 24, 179.

282. Wenger, K.; Bigler, L.; Suter, M.; Schönenberger, R.; Gupta, S.; Schulin, R.; J Environ. Qual. 2005, 34, 2187. 
283. Einhellig, F.; Souza, I.; J. Chem. Ecol. 1992, 18, 1.

284. Belz, R.; Hurle, K.; J. Chem. Ecol. 2004, 30, 175.

285. Tang, Ch.; Young, Ch.; Plant Physiol. 1982, 69, 155; Barbosa, T.; Ferreira, F.; De Souza, I., Barbosa, L.; Casali, V.; Planta Daninha 1982. $6,153$.

286. Caswell, E.; Tang, Ch.; de Frank, J.; Apt, W.; Revue Nénzatol. 1991, 14, 581.

287. Skene, K.; Plant Soil 2003, 248, 21.

288. Lamont, B.; Plant Soil 2003, 248, 1

289. Neumann, G.; Martinoia, E.; Trends Plant Sci. 2002, 7, 162.

290. Schenk, H.; Callaway, R.; Mahall, B.; Adv. Ecol. Res. 1999, $28,145$.

291. Bengough, A.; Bransby, M.; Hans, J.; McKenna, S.; Roberts, T.; Valentine, T.; J. Exp. Bot. 2006, 57, 437.

292. Jalali1, B.; Suryanarayana1, D.; Plant Soil 1974, 41, 425.

293. Schroth, M.; Hildebrand, D.; Ann. Rev. Phytopathol. 1964, 2, 101.

294. Rayan, P.; Delhaize, E.; Annu. Rev. Plant Physiol. Plant Mol. Biol. 2001, $52,527$.

295. Lewis, W.; Ploidy: Biological relevant, Plenum: New Cork, 1980, p. 180-182.

296. Niwa, Y.; Sasaki, Y.; Ecotoxicol. Environ. Saf. 2003, 55, 70.

297. Estilai, A.; Shannon, M. En Salt tolerance in relation to ploidy level in guayule; Janick, J.; Simon, J., eds.; Wiley: New Cork, 1993, cap 2.

298. Jaskani1, M.; Kwon1, S.; Kim1, D.; Euphytica 2005, 145, 259.

299. Wullschleger, S.; Sanderson, M.; McLaughlin, S.; Biradar, D; Rayburn, A.; Crop Sci. 1996, 36, 306.

300. Li, W.; Berlyn, G.; Ashton, P.; Am. J. Bot. 1996, 83, 15.
301. Kosuth, J.; Koperdakova, J.; Tolonen, A.; Hohtola, A.; Cellarova, E.; Plant Sci. 2003, 165, 515.

302. Orians, C.; Am. J. Bot. 2000, 87, 1749.

303. Cellarova, E.; Brutovska, R.; Daxnerova, Z.; Brunakova, K.; Weigel, R.; Acta Biotech. 1997, 17, 83.

304. Dhawan, O.; Lavania, U.; Euphytica 1996, 87, 81.

305. De Jesus-Gonzalez, L.; Weathers, P.; Plant Cell Rep. 2003, $21,809$.

306. Mable, B.; Trends Plant Sci. 2003, 8, 582.

307. Wu, H.; Pratley, J.; Ma, W.; Haig, T.; Theor. Appl. Genet. 2003, 107, 1477.

308. Foster, R.; Biol. Fertility Soils 1988, 6, 189.

309. Clegg, Ch.; Murray, P.; Iger Innovations 2002, 6, 36.

310. Dixon, R.; Nature. 2001, 411, 843.

311. Hirsch, A.; Dietz, W.; Bird, D.; Cullimore, J.; Tyler, B.; Poder, J.; Ecology 2003, 17, 858.

312. Bais, H.; Park, S.; Weir, T.; Callaway, R.; Vivanco, J.; Trens Plant Sci. 2004, 9, 26.

313. Fray, R.; Ann. Bot. 2002, 89, 245.

314. Dakora, F.; New Physiol. 2001, 65, 871.

315. Kneer, R.; Poulev, A.; Olesinski, A.; Raskin, I.; J. Exp. Bot. 1999, 339, 1553.

316. Ryan, A.; Kinkel, L.; Biol. Control. 1997, 10, 180.

317. Whipps, J.; Exp.Bot. 2001, 52, 487.

318. Dakora, F.; New Phytologist 2003, 158, 39.

319. Nicol, R.; Yousef, L.; Traquar, J.; Bernards, M.; Phytochemicals 2003, $64,257$. 